[Aus der bakteriologischen Abteilung des Pathologischen Instituts der Universität Berlin

(Abteilungsvorsteher: Prof. Dr. Morgenroth)

und der Medizinisehen Klinik der Universität Breslau.]

(Direktor: Geh. Medizinalrat Prof. Dr. Minkowski.)

\title{
Untersuchungen über die Genese des Rezidivs bei der experimentellen Trypanosomeninfektion.
}

Von

\section{Dr. Felix Rosenthal,}

Assistent der Klinik.

Im Verlaufe ihrer chemotherapeutischen Studien an Mäusen, die mit Trypanosomen infiziert waren, haben Ehrlich und seine Mitarbeiter Shiga, Franke, Röhl und Gulbransen auch das Problem der Rezidive bei Trypanosomenkrankheiten einer eingehenden experimentellen Untersuchung unterzogen und zuerst ihr Wesen mit voller Schärfe erfaBt. Bei der chemotherapeutischen Prüfung des der Gruppe der Azofarbstoffe angehörigen Trypanrots stellten Ehrlich und Shiga fest, daB das Trypanrot wohl für eine gewisse Zeit die Trypanosomen aus der Zirkulation von Mäusen und Ratten zum Verschwinden bringe, daB aber eine Dauerheilung nicht immer zu erreichen war. Nach einem bestimmten Zeitraum, innerhalb dessen das Blut der Versuchstiere sich als trypanosomenfrei erwies, trat das Rezidiv auf, dem die Tiere nun schnell erlagen. Aus dem Auftreten des Rezidivs ergab sich mit Notwendigkeit der SchluB, daB ein Teil der Trypanosomen in irgend einer Weise der trypanoziden Wirkung des chemotherapeutischen Agens entgehen müsse, und es lag nun die 
Frage nahe, warum die zurückgebliebenen Trypanosomen sich nicht sofort, sondern erst nach einer Zeit von Wochen und Monaten wieder vermehrten, während die Schutzwirkung des Heilmittels schon wenige 'Tage nach dessen Injektion verschwindet.

Um diese Frage zu klären, welches die Faktoren seien, die eine Vermehrung der zurückgebliebenen Trypanosomen nach Ablauf der TrypanrotSchutzwirkung verhinderten, wurde von Ehrlich, Shiga und Franke folgende Versuchsmethodik eingeschlagen: sie infizierten Mäuse, die durch Trypanrot von ihrer Mal de Caderas-Trypanosomeninfektion geheilt waren, nochmals mit diesen Trypanosomen nach, nachdem die trypanozide Wirkung des Trypanrot bereits abgeklungen war. Sie stellten nun fest, daß diese Neuinfektion nicht anging, ebenso wie alle Nachinfektionen, welche innerhalb von etwa 22 Tagen nach der Heilung der Infektion vorgenommen wurden. Es hat sich somit durch die Abheilung der Trypanosomeninfektion in den Versuchstieren eine echte, zeitlich begrenzte Immunität entwickelt.

Hatten Ehrlich und Shiga gehofft, aus dieser Erkenntnis heraus das Wesen der Rezidive erklären und ihre Genese auf eine vorübergehende, mehr oder weniger rasch abklingende Immunität und die Wirksamkeit residualer Keime „ungezwungen“ zurückführen zu können, so zeigte doch bald Ehrlich in weiteren mit Röhl und Gulbransen gemeinsamen Versuchen, daB das Problem des Rezidivs ein ungleich komplizierteres sei. Impft man nämlieh Trypanosomen im Stadium des Rezidivs auf eine Reihe ron Mäusen, die rorher mit dem Ausgangsstamm infiziert und durch Anwendung geeigneter chemotherapeutischer Agentien zur Heilung gebracht worden sind und damit immun gegen eine Nachinfektion mit dem gleichen Stamm geworden sind, und ferner auf eine zweite Reihe normaler Mäuse, so gẹt in beiden Reihen die Infektion gleich schnell an. Es haben sich somit in den Rezidivparasiten biologische Umsetzungen vollzogen, die Ehrlich auf Grund vielfach variierter Experimente dahin definieren konnte, daB die Erreger des Rezidivs nicht nur unemptindlich gegen die bei der Abheilung des Ausgangsstammes entstehenden Antikörper geworden waren, sondern auch ein vom Ausgangsstamm wesensdifferentes Rezeptorengerüst aufweisen.

Die so erzeugte Abänderung der Parasiten ist nicht obertlächlicher Art, sondern kann durch riele Monate und sogar auch Jahre hindurch bei Passagen durch normale Tiere unverändert fortgeführt werden. Während Ehrlich eine jahrelange Vererbung der Rezidirstammeigenschaften bei Mäuserezidirstämmen beobachtet hat, berichten Mesnil und Brimont und Neumann aus dem Morgenrothschen Laboratorium über Rezidirstämme, die ihre Rezidivstammeigenschafter allmählich wieder 
verloren. So beschreiben Mesnil und Brimont einen ron einem infizierten Togobock gewonnenen Trypanosomenstamm, der nach 19 Passagen in normalen Mäusen sich wieder zum Normalstamm zurückbildete. $\mathrm{Neu}$ mann beobachtete, daB im Verlanfe von ca. 20 Tierpassagen ein Rezidirstamm ron Nagana-Trypanosomen die bereits verlorengegangenen ursprünglichen Eigenschaften des Ausgangsstammes wieder annahm. Auch Braun and Teichmann machen bei ihren wichtigen Versuchen zur Immunisierung gegen Trypanosomen ähnliche Angaben. Sie berichten über einen Dourinestamm, welcher in 54 Passagen seine Rezidivstammeigenschaften rerlor und interessanterweise in seinen Übergangsetappen schrittweise verfolgt werden konnte. Auch wir verfügen über eine analoge Beobachtung, über die wir weiter unten berichten werden.

Wir haben nun in den folgenden Experimenten versucht, durch ein eingehenderes Studium der an die chemotherapeutische Heilung der experimentellen Trypanosomeninfektion sich anschlieBenden Immunität einen tieferen Einblick in die Prozesse zu gewinnen, welche zur Bildung des Rezidivstammes führen. Unsere in dieser Richtung unternommenen Versuche knüpfen an die wichtige Angabe Ehrlichs an, daB Normal-Trypanosomen, im Reagensglase mit Immunserum digeriert, sich unter gewissen quantitativen Bedingungen zum Rezidirstamm umwandeln.

„In dem Ausgangsstamm“, so deutet Ehrlich in seinem Aufsatz „über Partialfunktionen der Zelle" das Phänomen des differenten Verbaltens von Ausgangs- und Rezidivstamm, ,ist eine bestimmte einheitliche Art von Nutrizeptoren, die wir als Gruppe "A" bezeichnen wollen, in reichem Maße vorhanden. Werden nun die Parasiten innerhalb des Mäuseorganismus abgetötet und aufgelöst, so wirkt die Gruppierung "A" als Antigen und erzeugt nun einen Antikörper, der seiner Entstehung nach Verwandtschaft zur Gruppe "A" besitzt. Wenn man nun lebende Parasiten, sei es im Reagensglas, sei es in vivo, mit diesem Antikörper in Berührung bringt, so wird derselbe von den Trypanosomen verankert. Unter dem EinfluB dieser Besetzung erleiden in vivo die Parasiten diejenige biologische Abänderung, die zu dem Rezidivstamme überführt. Diese Abänderung geschieht in der Weise, da $B$ in dem neuen Stamm die ursprüngliche Gruppierung " $A$ "verschwindet und dafür eine neue Gruppierung, die als „B“ bezeichnet werden möge, auftritt........ Ist die Menge des Antikörpers sehr grob, so kann der Parasit sich überhaupt nicht mehr ernähren und stirbt ab. Man kann sich davon am einfachsten überzeugen, wenn man die Parasiten mit verschiedenen Mengen Antiserum im Reagensglase mischt. Bei den hohen Konzentrationen, die die Ernährungszufuhr vollkommen abbinden, erfolgt eine Abtötung der Parasiten; dagegen bildet sich ein Rezidivstamm bei den schwächeren Konzentrationen, die eine vita minima gestatten, in welcher die Mutation erfolgen kann. Diese Mutation ist also aussehließlich auf Hunger des Protoplasmas zurückzuführen, unter dessen Einfluß nene potentielle Anlagen der Trypanosomen zur Entfaltung kommen." 
Es vollzieht sich somit nach der Ehrlichschen Anschauung die Bildung des Rezidivstammes aus dem Ausgangsstamm in der Weise, daB bei Anwesenheit genügender, aber nicht letaler, spezifisch gegen den Ausgangsstamm gerichteter Antikörpermengen ein Umschlag der Trypanosomen in einer Richtung erfolgt, die die Erhaltung der Rasse auch unter den neuen Lebensbedingungen ermöglicht. Diese Vorstellung Ehrlichs lieB es also als das Nächstliegende erscheinen, daB zwischen dem trypanoziden Titer des Immunserums und seinem Vermögen, den Ausgangsstamm zum Rezidivstamm umzuformen, ein Parallelismus besteht.

Mit dem Mechanismus der biologischen Umwandlung der Normaltrypanosomen in Rezidivparasiten haben sich auch Levaditi und Mutermilch und Levaditi und $M c$ Intosh im AnschluB an die Mitteilungen Ehrlichs und seiner Schüler eingehend beschäftigt. Ihre Untersuchungen gehen insofern von einer etwas einseitigen Fragestellung aus, als sie sich ausschlieBlich mit dem Phänomen der Serumfestigkeit der Trypanosomen beschäftigen, mit der nach den geschilderten Befunden Ehrlichs, Röhls und Gulbransens das Wesen der Rezidivstämme sich keineswegs erschöpft. Sie stellten in Cbereinstimmung mit analogen, umfassenderen Versuchsergebnissen Ehrlichs, Röhls und Gulbransens fest, „que l'état réfractaire peut nâ̂tre, après un temps de contact in vitro extrêmement court (15 minutes)", und sie schließen aus ihren Beobachtungen, „que la vaccination des trypanosomes est précédée par une véritable sélection, engendrée par les principes trypanolytiques dans le tube à essai. Les rares parasites doués d'une certaine immunité naturelle à l'égard des anticorps, résistent à la trypanolyse et engendrent l'infection chez la souris." Ein ähnliches Verhalten zeigen nach Untersuchungen von Levaditi und Stanesco die Spirillen des europäischen Rückfallfiebers (Spirochaeta Obermeyeri), während die Spirillen der Hühnerspirillose diese beträchtliche in der Richtung der Serumfestigkeit tendierende Plastizität bei Immunserumkontakt nicht aufweisen.

Während Levaditi und seine Mitarbeiter mit Meerschweinchenimmunserum in ihren Versuchen arbeiteten, tritt nach unseren Erfahrungen bei Mäuseimmunseren eine Trypanolyse in vitro überhaupt nicht oder in nur sehr geringem MaBe in die Erscheinung. DaB dem Mäuseimmunserum nicht etwa im Gegensatz zum Meerschweinchenimmunserum trypanolytische Eigenschaften fehlen, ergibt sich mit Sicherheit aus unseren Beobachtungen, daB intravenös injizierte Normal-Trypanosomen bei Mäusen, die 24 Stunden vorher durch Brechweinstein von ihrer Normal-Naganainfektion geheilt worden waren, einer rapiden Trypanolyse in der Zirkulation unterliegen. Möglicher- 
weise eröffnen für dieses differente Verhalten des Mäuseimmunserums in vitro und in vivo die Befunde von Ritz ein Verständnis, wonach das in der üblichen Weise gewonnene Mäuseserum nur Mittelstück, nicht vollständiges Komplement enthält. Diese Befunde legen es jedenfalls nahe, daB vielleicht beim Entbluten der Mäuse antikomplementäre Prozesse sich im Serum abspielen, die beim Meerschweinchenserum nicht in Aktion treten. Wir sind mit weiteren Untersuchungen in dieser Richtung beschäftigt und möchten an dieser Stelle nur bemerken, daß wir analogen Verhältnissen bei hämolytischen Taubenblut-Mäuseambozeptoren begegnet sind. Während derartige Immunsera, entsprechend den Beobachtungen von Ritz bei Rinderblut-Mäuseimmunserum, in aktivem Zustand keinerlei hämolytische Wiriung auf Taubenblut im Reagensglase entfalten, werden die Taubenblutkörperchen bei intravenöser Injektion in entsprechend vorbehandelte Mäuse in der Zirkulation auBerordentlich schnell aufgelöst, ein Beweis, daB in vivo Komplement bei Mäusen vorhanden sein muB.

Von der Absicht ausgehend, zunächst die optimalen zeitlichen Bedingungen zu fixieren, unter denen sich kei Kontakt der Trypanosomen mit spezifischem Immunserum der Umschlag des Normalstammes in den Rezidivstamm rollzieht, sind wir in unseren ersten Versuchen so vorgegangen, daß wir auf der Höhe der Infektion befindliche Normal-Naganamäuse mit $0.25 \mathrm{~cm}$ Tartarus stibiatus 1:1000 subkutan abheilten, dann in Abständen von 3, 6, 8, 24, 48 und 72 Stunden nach der Finführung des chemotherapeutischen Agens die Versuchstiere in je 2 ccm physiologischer Kochsalzlösung entbluteten und je $1^{\mathrm{cm}}$ dieser Aufschwemmung mit $1^{\mathrm{ccm}}$ einer +++ Normal-Nagana-Trypanosomenaufschwemmung in physiologischer Kochsalzlösung während 45 Minuten bei Zimmertemperatur digerierten. Für die Wahl des Kaliumantimonyltartrats war vor allem die rasche Wirkung und das rasche Abklingen der chemotherapeutischen Wirksamkeit des Brechweinsteins maßgebend, der nach unseren Erfahrungen hereits 3 Stunden nach seiner Einführung keine prophylaktische Wirkung mehr entfaltet. Bei Verwendung der Seren ganz frisch abgeheilter Tiere haben wir den Serumkontalt der Parasiten auf 45 Minuten ausgedehnt, um möglichst optimale Reaktionsberingungen zu schaffen. In späteren Versuchen erwies sich uns ein Serumkontakt von 10 bis 15 Minuten als ausreichend.

Nach Ablauf von 45 Minuten wurden dann Normalmäuse mit $0 \cdot 2$ cem der Mischung Trypanosomen+Immunserum intraperitoneal infiziert, die, wenn die Infektion anging, bei einem reichlichen Trypanosomengehalt des Blutes mit $\mathbf{0 . 2 5} \mathrm{cm}$ Tartarus stibiatus $1: 1000$, bezw. mit $\mathbf{0 . 5} 5^{\mathrm{cm}}$ Arsacetin $1: 100$ subkutan abgeheilt wurden. 
Als Kriterium für die biologische Umwandlung des Normalstammes zum Rezidivstamm diente die 24 bezw. 48 Stunden nach der Abheilung der Versuchstiere erfolgende Nachinfektion mit dem Normalausgangsstamm. Ging diese Infektion an, vermochte also die Abheilung der ersten Infektion eine erneute Infektion mit dem Ausgangsstamm nicht zu verhindern, so war damit entsprechend den biologischen Differenzen, wie sie als charakteristisch zwischen Ausgangsstamm und seinen Rezidivstämmen beschrieben worden sind, die Umwandlung des vorgeimpften Stammes zum Rezidivstamm gegeben. Versagte dagegen die Nachinfektion des Normalstammes, rief also die Abheilung des in vitro mit Immunserum digerierten Normalstammes eine Immunität gegen eine Neuinfektion mit dem gleichen Normalstamm hervor, so lieb sich aus dieser Immunitätsreaktion ersehen, daB der Umschlag des Ausgangsstammes zum Rezidivstamm trotz des Kontaktes mit dem Serum der abgeheilten Tiere unterblieben war.

Während das Serum der nach 3, 6, 8 und 24 Stunden nach Applikation des Brechweinsteins entbluteten Tiere trotz des Kontaktes von 45 Minuten, der in einigen Fällen sogar bis zu 24 Stunden ausgedehnt wurde, ohne jeden EinfluB auf die hinzugefügten Trypanosomen blieb, gelang es uns durch Behandlung der Ausgangsparasiten im Reagensglase mit dem Serum eines $48 \mathrm{Stunden}$ nach der chemotherapeutischen Behandlung getöteten Tieres einen Rezidivstamm aus dem Ausgangsstamm zu gewinnen. Diese Umprägung des Ausgangsstammes zum Rezidivstamm im Reagensglase blieb bei Benutzung eines 72 stündigen Serums aus.

Die folgenden Tabellen I und II geben diese Versuche wieder, deren Einzelheiten aus den Protokollen ersichtlich sind. Dabei waren, um zu einwandsfreien Resultaten zu gelangen, folgende Kontrolltiere notwendig, die entsprechend den Angaben der folgenden Tabellen eingestellt wurden. Hierzu gehören:

1. Infektionskontrollen, d. h. Tiere, welche mit der gleichen Menge Trypanosomen wie die Tiere des eigentlichen Versuches, nur ohne Immunserumzusatz infiziert wurden (z. B. Tabelle I M. 68a und M. 68b) und welche die Intensität und die Fntwicklung der unbeeinflußten Infektion demonstrieren.

2. Prophylaktische Serumkontrollen, d. h. Tiere, welche, mit der im eigentlichen Versuch verwendeten Immunserummenge vorbehandelt, anzeigen, daB keine prophylaktische Wirkung mehr von dieser ausgeht (z. B. Tabelle I, M. $69 \mathrm{a}$ und M. $69 \mathrm{~b}$ ).

3. Prophylaktische Tartarus stibiatus-(T.), bzw. Arsacetin - (A) Kontrollen, d. h. Tiere, welche mit dem Heilmittel vorbehandelt, anzeigen, daß keine für die Beurteilung der Nachinfektion bedeutungsvolle prophylaktische chemotherapeutische Wirkung mehr von diesem 


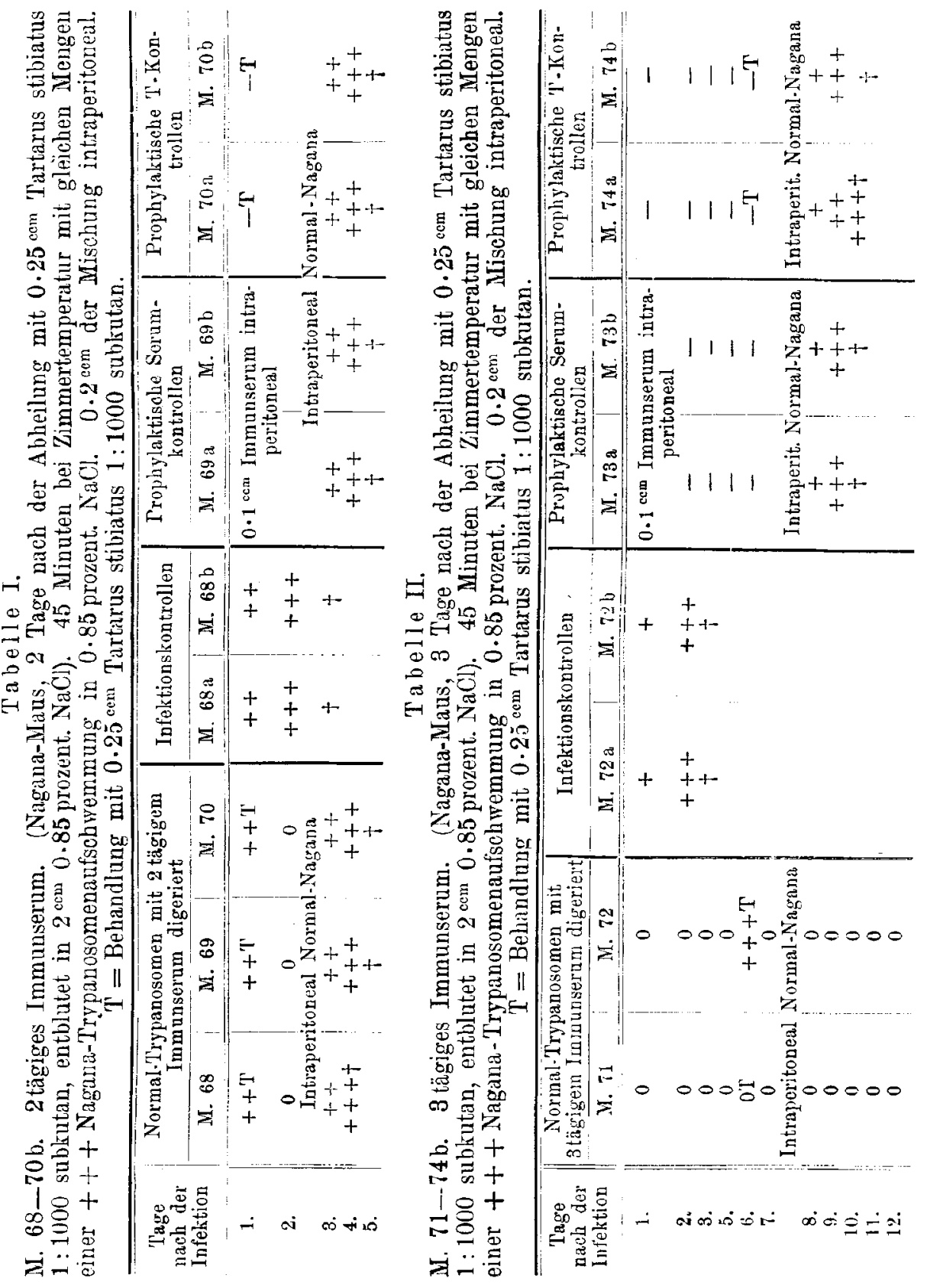


ausgeht (z. B. M. $70 \mathrm{a}$ und M. $70 \mathrm{~b}$ in Tabelle $\mathrm{I}$ und Pr. $3 \mathrm{a}$ und $3 \mathrm{~b}$ in Tabelle III).

3. Rezidivkontrollen, d. h. Tiere, die nach der Heilung nicht nachinfiziert wurden und den Zeitpunkt des eventuellen Rezidiveintrittes veranschaulichen, z. B. Pr. $4 \mathrm{a}$ und $4 \mathrm{~b}$ in Tabelle III. (Diese Kontrollen wurden nicht in allen Versuchen angesetzt.)

Es geht somit aus Versuch I hervor, daB unter dem EinfluB ron Immunserum in vitro, das von einer Maus 48 Stunden nach der Abbeilung gewonnen war, derAusgangsstamm die Eigenschaften von Rezidivstämmen annimmt. Dieser Rezidivstamm entwickelt sich, obne daB eine Trypanozidie des Serums auch nur angedeutet in die Erscheinung tritt: die Infektion der mit Immunserum im Reagensglase digerierten Trypanosomen geht ebenso schnell an, wie die der Infektionskontrollen, sie befindet sich bereits 24 Stunden nach der intraperitonealen starken Infektion bei sämtlichen Versuchstieren auf der Höhe ihrer Entwickelung. DaB sich in der Tat unter dem Einflusse des Antiserums in den Ausgangstrypanosomen tiefgreifende biologische Umwandlungen in der Richtung des Rezidirstammes vollzogen haben, zeigt das Resultat der Nachimpfung mit dem Normalstamm, der sich in den abgeheilten Mäusen ungehemmt vermehrt und schlieBlich ibren Tod herbeiführt. Es vermögen somit die bei der Abtötung des mit Immunserum behandelten Normalstammes entstehenden Antikörper nicht den nachgeimpften Normalstamm anzugreifen, es bestehen mithin, wie die Immunitätsreaktion demonstriert, zwischen dem in vitro mit Immunserum behandelten und dem unberührten Ausgangsstamm die charakteristischen Differenzen, wie sie für Rezidivstamm und Ausgangsstamm typisch sind. Diese plötzliche sprunghafte Bildung des Rezidirstammes aus dem Ausgangsstamm im Reagensglase zeigt alle Characteristica der echten Mutation im Sinne de Vries': Sie entsteht sprunghaft, und der neue erworbene Charakter ist erblich, wie wir uns in 12 Passagen überzeugen konnten.

Zeigt bereits dieser Versuch $I$, daB die Trypanozidie des spezifischen Serums und seine Fähigkeit, den Ausgangsstamm in vitro zum Rezidivstamm umzuprägen, in keinem Abhängigkeitsverhältnis zueinander zu stehen scheinen, so stellt das folgende Experiment II das ergänzende Gegenstück hierzu dar, insofern, als hier trotz ausgeprägtester Trypanozidie des 72 stündigen Immunserums die Umwandlung des Ausgangsstammes zum Rezidivstamm ausbleibt (S. 495).

Wir sehen hier als Ausdruck des trypanoziden Vermögens des Immunserums bei einem Tiere (II. 72) die Infektion auBerordentlich verspätet 
gegenüber den Infektionskontrollen angehen (M. 72a und M. 72b), die bereits nach einem Tage nach der intraperitonealen Infektion reichlich Trypanosomen in der Zirkulation enthalten; bei einem Versuchstiere (M. 71) reicht sogar die verwendete Immunserummenge aus, um ein Angehen der primären Infeltion anscheinend definitiv zu verhindern. Obwohl also hier Serumkonzentrationen zur Verwendung gelangten, die sich in unmittelbarer Nähe der Dosis letalis certe efficax bewegen, sehlägt der Ausgangsstamm nicht zum Rezidivstamm um, wie dies das Versagen der Nachinfektion mit Normalstamm beweist. Da die Möglichkeit bestand, $\mathrm{daB}$ die in M. 71 der trypanoziden Serumwirkung erliegenden Trypanosomen noch vor ihrer Vernichtung Rezidivstammeigenschaften angenommen haben konnten, so haben wir auch M. 71 7 Tage nach der Infektion von neuem mit Normaltrypanosomen nachinfiziert. Aus dem Ausbleiben auch dieser Nachinfektion geht hervor, daB die untergegangenen Trypanosomen bis zum Moment ihres Todes die Eigenschaften von Normalindividuen bewabrt haben.

Wir sehen somit in Tabelle I trotz des Fehlens einer prophylaktischen Serumwirkung sich den Rezidivstamm aus dem Normalstamm entwickeln, während in Tabelle II bei guter Prophylaxe kein Rezidirstamm bei Serumkontakt aus dem Normalstamm entsteht. Es geht hieraus hervor, dab der trypanozide Titer eines spezifischen Trypanosomenimmunserums nicht für die Cmbildung des Normalstammes zum Rezidirstamm den maBgebenden Faktor darstellt.

Nach diesen Feststellungen sind wir an der Hand eines größeren Versuchsmaterials der Frage näher getreten, ob die Dissonanz zwischen Trypanozidie und Rezidirstammbildungsvermögen, wie wir sie soeben beschrieben haben, auch bei anderen, zeitlich verschiedenen spezifischen Seren zutage tritt.

In den folgenden Tabellen geben wir weitere Typen unserer Reagensglasversuche wieder.

Im Versuch III besteht ein gewisser Parallelismus zwischen dem Grade der prophylaktischen Wirkung des Serums und seiner Fähigleit, den Normalstamm in den Rezidirstamm umzuwandeln. In diesem Versuche wurde das Serum einer 4 Tage nach der Abheilung (mit $2 \times 0.005$ Arsacetin) befindlichen Maus verwendet, das mit gleichen Mengen einer +++ Normal-Try panosomenaufschwemmung 10 Minuten bei $37^{\circ}$ in vitro digeriert wurde. Während bei den Infektionskontrollen Pr. $2 \mathrm{a}$ und Pr. $2 \mathrm{~b}$ bereits 24 Stunden nach der intraperitonealen Impfung die Infektion deutlich entwickelt ist, erscheinen in den Versuchstieren Pr. 2 bis Pr. 5, die mit der gleichen, aber der Immunserumwirkung 


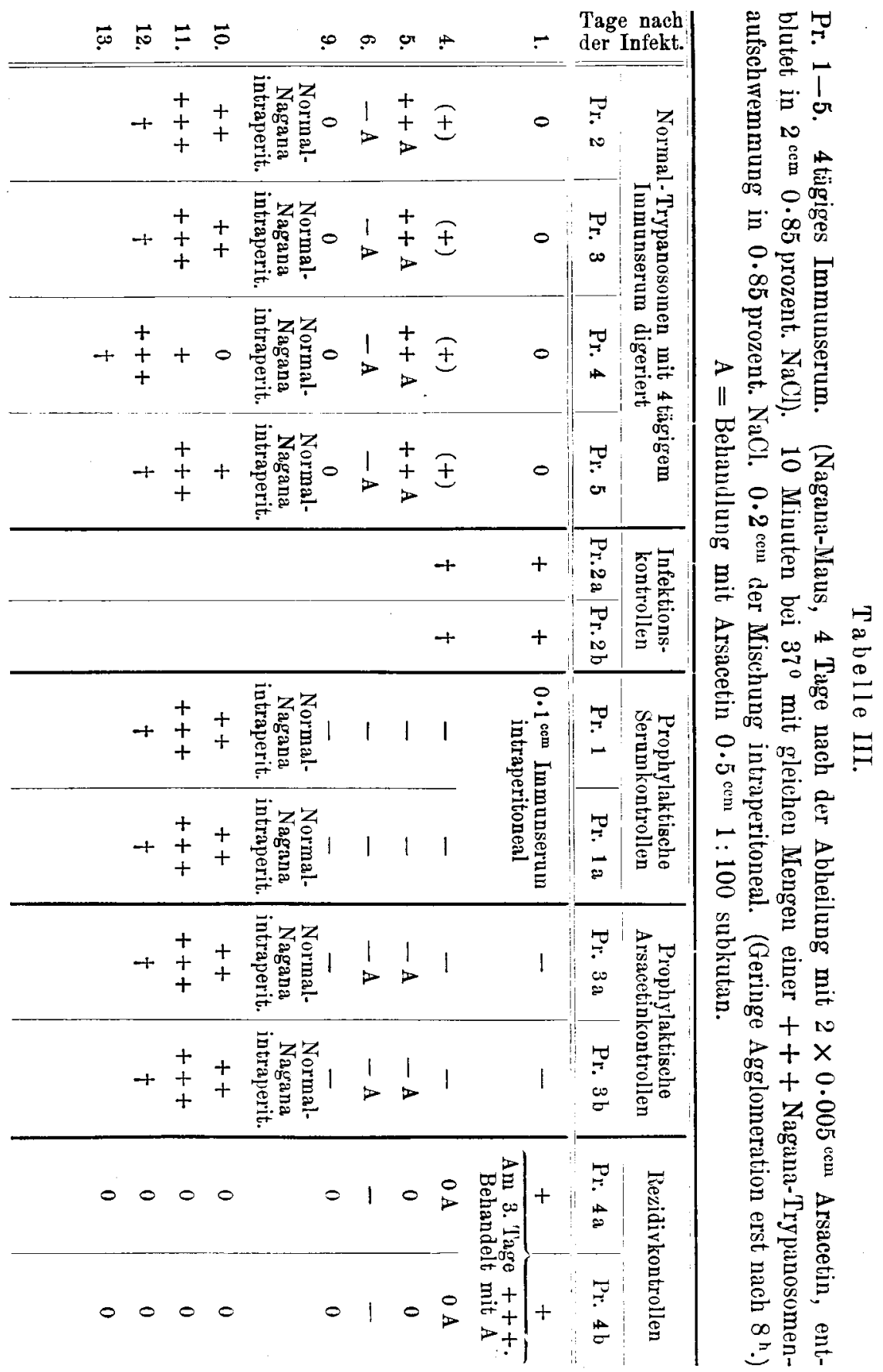


ausgesetzten Trypanosomenmenge infiziert sind, die ersten Parasiten erst am 4. Versuchstage spärlich in der Zirkulation zu einer Zeit, wo die Infektionskontrollen der Trypanosomenseptikämie bereits erlegen sind. Diese verspätet auftretenden Parasiten sind zu Trägern von Rezidivstammeigenschaften geworden; denn, wie das Resultat der Nachimpfung mit NormalNagana nach erfolgter Abheilung zeigt, ruft ihre Abheilung keine Immunität gegen dem nachinfizierten Ausgangsstamm hervor, obwohl sie sich von ihm ursprünglich ableiten.

Die gleichen Verhältnisse zeigt der nächste Versuch IVa.

\section{Tabelle IVa.}

Pr. 64-68. 5 tägiges Immunserum. (2 Nagana-Mäuse, 5 Tage nach der Abheilung mit $2 \times 0.005^{\mathrm{cm}}$ Arsacetin, entblutet in $4.0^{\mathrm{ccm}} 0.85 \mathrm{pro}$ zentiger $\mathrm{NaCl}$.) Absteigende Mengen des Immunserums mit $0.6^{\mathrm{ecm}}$ einer ++ Nagana-Trypanosomenaufschwemmung in 0.85 proz. $\mathrm{NaCl} 10$ Minuten bei Zimmertemperatur digeriert. $\mathbf{0 . 3} \mathrm{cm}$ der Mischung intraperitoneal. $A=$ Behandlung mit Arsacetin $0 \cdot 6^{\mathrm{cem}} 1: 100$ subkutan.

\begin{tabular}{|c|c|c|c|c|c|}
\hline \multirow{3}{*}{$\begin{array}{c}\text { Tage } \\
\text { nach der } \\
\text { Infektion }\end{array}$} & \multicolumn{3}{|c|}{$\begin{array}{l}0.6^{\mathrm{ccm}} \text { Normal-Trypanosomen mit } 5 \text { tägig. } \\
\text { Immunserum digeriert in Mengen ron }\end{array}$} & \multicolumn{2}{|c|}{ Infektionskontrollen } \\
\hline & $0.1^{\mathrm{cm}}$ & $0.3 \mathrm{cem}$ & $0 \cdot 5^{\mathrm{ecm}}$ & & \\
\hline & Pr. 64 & Pr. 66 & Pr. 68 & Pr. $66 \mathrm{a}$ & Pr. $66 \mathrm{~b}$ \\
\hline 1. & 0 & 0 & 0 & + & + \\
\hline 3. & 0 & 0 & 0 & $++t$ & $++t$ \\
\hline & & & & $\mathrm{Am}$ & tot. \\
\hline 5. & $+t$ & 0 & ++ & & \\
\hline 6. & $\begin{array}{c}+++A \\
+ \text { Intraperit. } \\
\text { auf Pr. 64a }\end{array}$ & 0 & $\begin{array}{l}\stackrel{++A}{+}+{ }^{2} \\
+ \text { Intraperit. } \\
\text { auf Pr. } 68 a\end{array}$ & & \\
\hline 10. & & 0 & & & \\
\hline 12. & & 0 & & & \\
\hline 16. & $I^{\prime}$ & 0 & & & \\
\hline
\end{tabular}

Hier tritt die trypanozide Wirliung des 5 tägigen Immunserums noch deutlicher als in dem vorangehenden Versuch in die Erscheinung. Zur Gewinnung des Immunserums wurden 2 Naganamäuse 5 Tage nach ibrer Abheilung mit $2 \times 0.005$ Arsacetin (in Abständen von 24 Stunden subkutan appliziert) in $4.0 \mathrm{~cm} 0.85$ Prozent $\mathrm{NaCl}$ entblutet. Absteigende Mengen des Immunserums wurden dann, wie in der Tabelle angegeben, mit $0 \cdot 6^{\mathrm{cm}}$ einer ++ Normal-Nagana-Trypanosomenaufschwemmung $10 \mathrm{Min}$. bei Zimmertemperatur im Reagensglase digeriert und mit physiologischer Kochsalzlösung auf gleiche Volumina aufgefüllt. Je $0.3 \mathrm{~cm}$ der verschie- 
denen Serumkonzentrationen zusammen mit den Trypanosomen wurden den in dem Protokoll angeführten Versuchstieren Pr. 64, 66, 68 intraperitoneal infiziert. Als Infektionskontrollen dienten die Mäuse Pr. 66a. und $66 \mathrm{~b}$, die mit der gleichen Menge unbehandelter Normal-Trypanosomen infiziert wurden. Die Stärke der gesetzten Infektion ist aus dem Verlauf der unbeeinfluBten Infektion bei Pr. 66a und Pr. 66 b ersichtlich. Bereits am nächsten Tage sind reichlich Trypanosomen in der Zirkulation der Kontrolltiere, die am 4. Tage nach der Infektion ihrer Septikämie erliegen. Wie die Protokolle der Versuchstiere Pr. 64, 66, 68 nun zeigen, erleidet unter dem EinfluB des Immunserumkontaktes der Normal-Trypanosomen im Reagensglase die Infektion eine erhebliche Verzögerung, indem erst am 5. Tage reichlich Trypanosomen in der Zirkulation der Mäuse nachzuweisen sind. Bei Pr 66 erweist sich die verwendete Serummenge von $0.3^{\mathrm{cm}}$ auf $0.6^{\mathrm{cm}}$ einer +++ Normal-Naganaaufschwemmung als aus. reichend, um ein Angehen der Infektion definitiv zu verhindern. Die Versuchsanordnung erfuhr in diesem Versuch dadurch eine Änderung, daB bei Pr. 64 und Pr. 68 die chemotherapeutische Behandlung bei $\mathrm{zu}$ weit vorgeschrittener Infektion erst einsetzte, so daB sie erfolglos blieb und die Tiere an ihrer Infektion zugrunde gingen. Die Parasiten wurden daher durch tberimpfung des Herzblutes jeder einzelnen Maus auf frische Mäuse (Tabelle IVb, Pr. 64a und 68a) übertragen.

Tabel]e IVb.

\begin{tabular}{|c|c|c|c|c|c|c|c|c|}
\hline \multirow{2}{*}{ 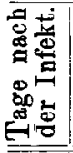 } & \multirow{2}{*}{ Pr. 64 a } & \multirow{2}{*}{ Pr. $68 \mathrm{~b}$} & \multirow{2}{*}{$\begin{array}{l}\text { Rezidiv. } \\
\text { kontrolle } \\
\text { 2u } \\
\text { Pr. } 64 \text { a }\end{array}$} & \multirow{2}{*}{$\begin{array}{l}\text { Rezidiv- } \\
\text { kontrolle } \\
\text { zu } \\
\text { Pr. } 68 \mathrm{a}\end{array}$} & \multicolumn{2}{|c|}{$\begin{array}{c}\text { Prophylaktische } \\
\text { A-Kontrollen }\end{array}$} & \multicolumn{2}{|c|}{$\begin{array}{c}\text { Prophylaktische } \\
\text { A-Kontrollen }\end{array}$} \\
\hline & & & & & Pr. $64 \mathrm{~b}$ & Pr. $64 \mathrm{c}$ & Pr. 68b & Pr. $68 \mathrm{c}$ \\
\hline 1. & + & 0 & + & 0 & - & - & - & - \\
\hline 2. & $++A$ & 0 & $++A$ & 0 & $\mathbf{A}$ & $\mathbf{A}$ & - & - \\
\hline 4. & $\begin{array}{c}0 \\
\text { Normal- } \\
\text { Nagana } \\
\text { intraperit. }\end{array}$ & + & 0 & + & $\begin{array}{c}\text { Normal- } \\
\text { Nagana } \\
\text { intraperit. }\end{array}$ & $\begin{array}{c}\text { Normal. } \\
\text { Nagana } \\
\text { intraperit. }\end{array}$ & - & - \\
\hline 5. & +++ & $+++\mathbf{A}$ & 0 & $+++A$ & ++ & $++t$ & $\mathbf{A}$ & $\mathbf{A}$ \\
\hline 6. & $t$ & 0 & 0 & 0 & +++ & $t$ & - & - \\
\hline 7. & & $\begin{array}{c}0 \\
\text { Normal- } \\
\text { Nagana } \\
\text { intraperit. }\end{array}$ & 0 & 0 & $t$ & & $\begin{array}{c}\text { Normal. } \\
\text { Nagana } \\
\text { intraperit. }\end{array}$ & $\begin{array}{l}\text { Normal- } \\
\text { Nagana } \\
\text { intraperit. }\end{array}$ \\
\hline 8. & & $(+)$ & 0 & 0 & & & $(+)$ & $(+)$ \\
\hline 10. & & +++ & 0 & 0 & & & $+t+$ & $+t+$ \\
\hline 11. & & $\dot{t}$ & 0 & 0 & & & $t$ & $t$ \\
\hline
\end{tabular}


Die angehenden Trypanosomen erwiesen sich hierbei als typische Rezidivparasiten, da die an die Abheilung derselben sich anschlieBende Immunität gegenüber der Nachinfektion mit Normal-Naganastamm rersagte.

Ober die Schnelligkeit, mit der die Umwandlung des Ausgangsstammes zum Rezidirstamm sich vollzieht, geben diese Versuche keinen AufschluB. Wenn auch der Kontakt der Normalindividuen mit Immunserum im Reagensglase sich nur auf 10 Minuten bei Zimmertemperatur erstreckt, so ist es doch bei der beträchtlichen Verzögerung der Infektion in diesen Fällen immerhin sehr wahrscheinlich, daB der eigentliche ProzeB des Umschlages vom Ausgangsstamm zum Rezidivstamm während der mehrere Tage bestehenden Latenz der Infektion im Tierkörper stattfindet. Für die hier vorliegenden Verhältnisse würde die Annahme, daß die trypanoziden Immunkörper das ätiologische Moment für die Umwandlung des Ausgangsstammes zum Rezidivstamm bilden, als erklärendes Prinzip genügen. Daß diese Vorstellungen von der Genese des Rezidivs jedoch der Mannigfaltigkeit der sich im Experiment darbietenden Erscheinungswelt nicht gerecht werden, ist bereits bei Versuch I und II gezeigt worden und ergibt sich gleichfalls aus den folgenden Typen unserer Reagensglasversuche.

Tabelle V und VI zeigen analoge Verhältnisse wie Versuch II bei einem 6 tägigen, bezw. 11 tägigen Immunserum: starke Trypanozidie des Serums, ohne dab der mit dem Serum behandelte, verzögert sich entwickelnde Stamm Rezidirstammeigenschaften angenommen hat. Versuch $\mathrm{V}$ erscheint in dieser Hinsicht besonders markant, da die im Versuch rerwendeten Serumkonzentrationen hart an die Dosis letalis certe efficax grenzen, wie dies das Ausbleiben der Infektion bei Maus Pr. 7 und Pr. 10 beweist. Auch bei den Mäusen Pr. 8 und 9, bei den die Infektion schlieBlich angeht, tritt die trypanozide Fähigkeit des verwendeten 6 tägigen Immunserums deutlich in die Erscheinung, indem bei beiden Tieren die Infektion sich erheblich verzögert gegenüber den Kontrollen entwickelt. Die Infektionskontrolltiere Pr. 7a und Pr. 7 b sind am 3. 'Tage nach der intraperitonealen Infektion gestorben, dagegen befindet sich bei Pr. 8 erst am 4. Tage die Infektion auf der Höhe ihrer Entwicklung und bei Pr. 9 ist sogar die Infektion erst am 9. Versuchstage, also 6 Tage nach dem Tode der Kontrollmäuse, voll ausgeprägt.

Trotzdem also Serummengen zur Anwendung gelangen, die entsprechend ihrer erheblichen prophylaktischen Wirkung eine beträchtliche trypanozide Wirkung erhalten, erfolgt bei Pr. 8, Pr. 9, Pr. 115 kein Umschlag des Normalstammes zum Rezidivstamm. Denn, wie das Ergebnis der Nachinfektion mit dem Normalstamm demonstriert, versagt bei diesen Tieren die Nachinfektion, es hat sich somit mit der Abheilung der mit 


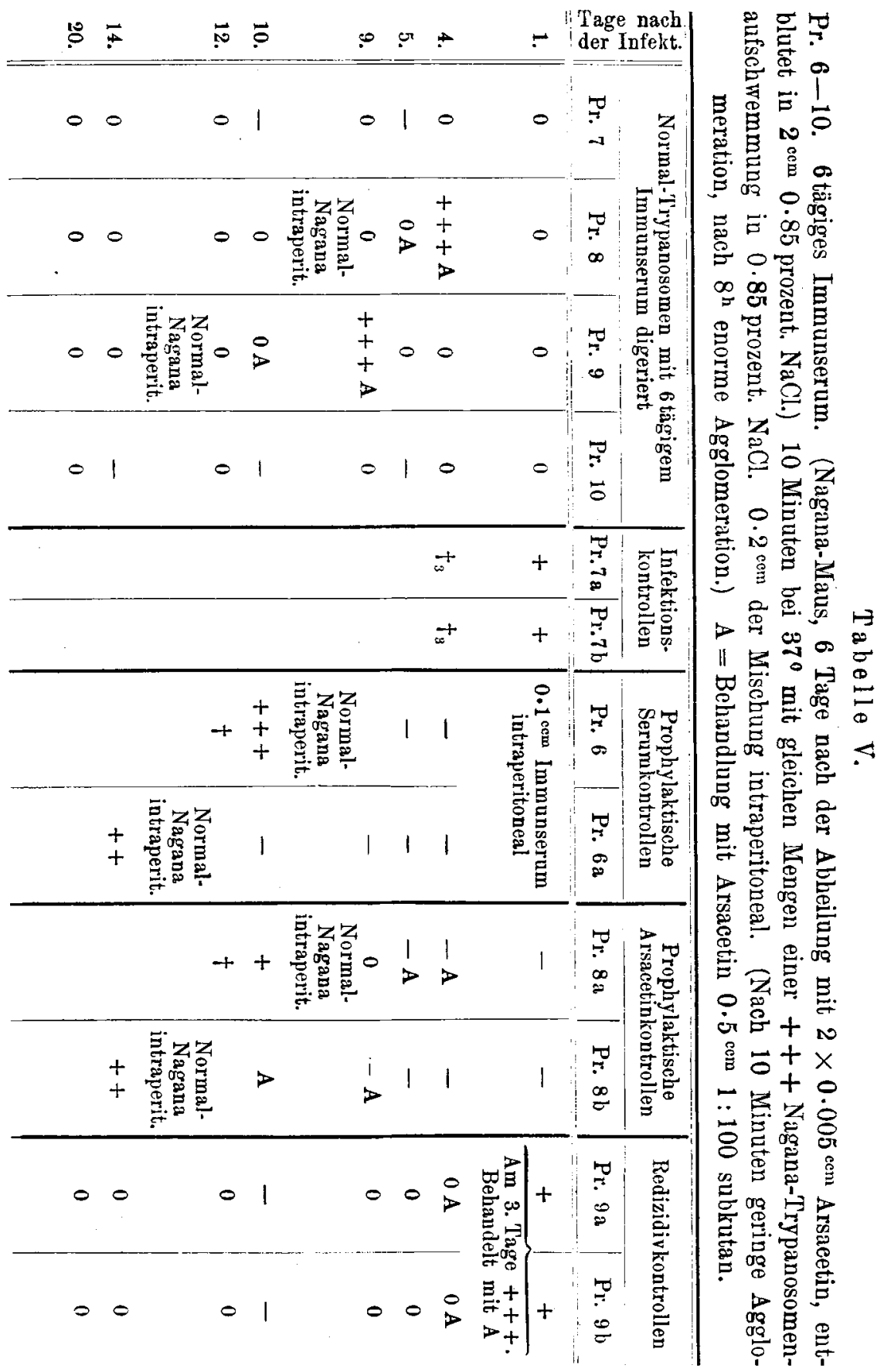


Immunserum digerierten Parasiten eine echte Immunität gegen den Ausgangsstamm ausgebildet, mit anderen Worten: die der spezifischen Wirkung des Immunserums ausgesetzten Normal-Trypanosomen haben trotz der starken trypanoziden Kraft der Sera die charakteristischen Eigenschaften des Ausgangsstammes bewahrt. Trypanozidie und Rezidivstammbildungsvermögen eines Trypanosomenimmunserums stehen somit nicht in einer direkten Proportion zueinander, sondern scheinen roneinander unabhängig zu sein.

\section{Tabelle VI.}

Pr. 115-118b. 11 tägiges Immunserum. (1 Nagana-Maus, 11 Tage nach der Abheilung mit $2 \times 0.005^{\mathrm{cm}}$ Arsacetin, entblutet in $2.0^{\mathrm{ccm}} 0.85$ prozentiger $\mathrm{NaCl}$.) $\quad 0 \cdot 5^{\mathrm{cem}}$ des Immunserums mit $0 \cdot 5^{\mathrm{cm}}$ einer +++ NaganaTrypanosomenaufschwemmung in 0.85 prozentiger $\mathrm{NaCl} 10$ Minuten bei Zimmertemperatur digeriert. $0.2^{\mathrm{cem}}$ der Mischung intraperitoneal. $\mathrm{A}=$ Behandlung mit $0.5^{\mathrm{cem}}$ Arsacetin 1:100 subkutan.

\begin{tabular}{|c|c|c|c|c|c|c|}
\hline \multirow{2}{*}{$\begin{array}{l}\text { Tage nach } \\
\text { der In- } \\
\text { fektion }\end{array}$} & \multirow{2}{*}{$\begin{array}{l}\text { Normal-Try- } \\
\text { panosomen } \\
\text { mit } 11 \text { täg. } \\
\text { Immunserum } \\
\text { digeriert } \\
\text { Pr. } 115\end{array}$} & \multicolumn{2}{|c|}{ Infektionskontrollen } & \multicolumn{2}{|c|}{$\begin{array}{l}\text { Prophylaktische } \\
\text { Arsacetinkontrollen }\end{array}$} & \multirow{2}{*}{$\begin{array}{l}\text { Prophylak- } \\
\text { tische Serum- } \\
\text { kontrolle } \\
\text { Pr. } 115 \text { a }\end{array}$} \\
\hline & & Pr. $116 a$ & Pr. $116 \mathrm{~b}$ & Pr. $117 \mathrm{a}$ & Pr. $117 b$ & \\
\hline 1. & 0 & + & + & - & - & $\begin{array}{c}0 \cdot 1 \mathrm{cem} \\
\text { Immnnserum } \\
\text { intraperit. }\end{array}$ \\
\hline 2. & 0 & +++ & ++ & - & - & - \\
\hline 3. & 0 & $t$ & $++t+$ & - & - & - \\
\hline 4. & $(t)$ & & & 一 & - & 一 \\
\hline 5. & $++A$ & & & $-\mathrm{A}$ & $-A$ & - \\
\hline 6. & $-A$ & & & $-A$ & $-A$ & - \\
\hline 10. & $\begin{array}{c}0 \\
\text { Normal- }\end{array}$ & & & Normal- & Normal. & Normal. \\
\hline & $\begin{array}{c}\text { Nagana intra- } \\
\text { peritoneal }\end{array}$ & & & $\begin{array}{l}\text { Nagana } \\
\text { intraperit. }\end{array}$ & $\begin{array}{c}\text { Nagana } \\
\text { intraperit. }\end{array}$ & $\begin{array}{l}\text { Nagana intra- } \\
\text { peritoneal }\end{array}$ \\
\hline 11. & 0 & & & + & $\perp$ & + \\
\hline 12. & 0 & & & +++ & $++t$ & +++ \\
\hline 15. & 0 & & & $\begin{array}{c}\text { Am folge } \\
\text { beide }\end{array}$ & $\begin{array}{l}\text { den Tage } \\
\text { läuse }+\end{array}$ & $\begin{array}{l}\text { Am folgenden } \\
\text { Tage Maus }+\end{array}$ \\
\hline
\end{tabular}

Dies hommt auch in dem folgenden Versuch VII zum Ausdruck, der in Ubereinstimmung mit Protokoll I bei Verwendung eines 13 tägigen Immunserums den Nachweis liefert, daB auch umgekehrt bei Fehlen trypanozider Eigenschaften das Immunserum exquisit rezidivstammbildende Eigenschaften besitzen kann. 


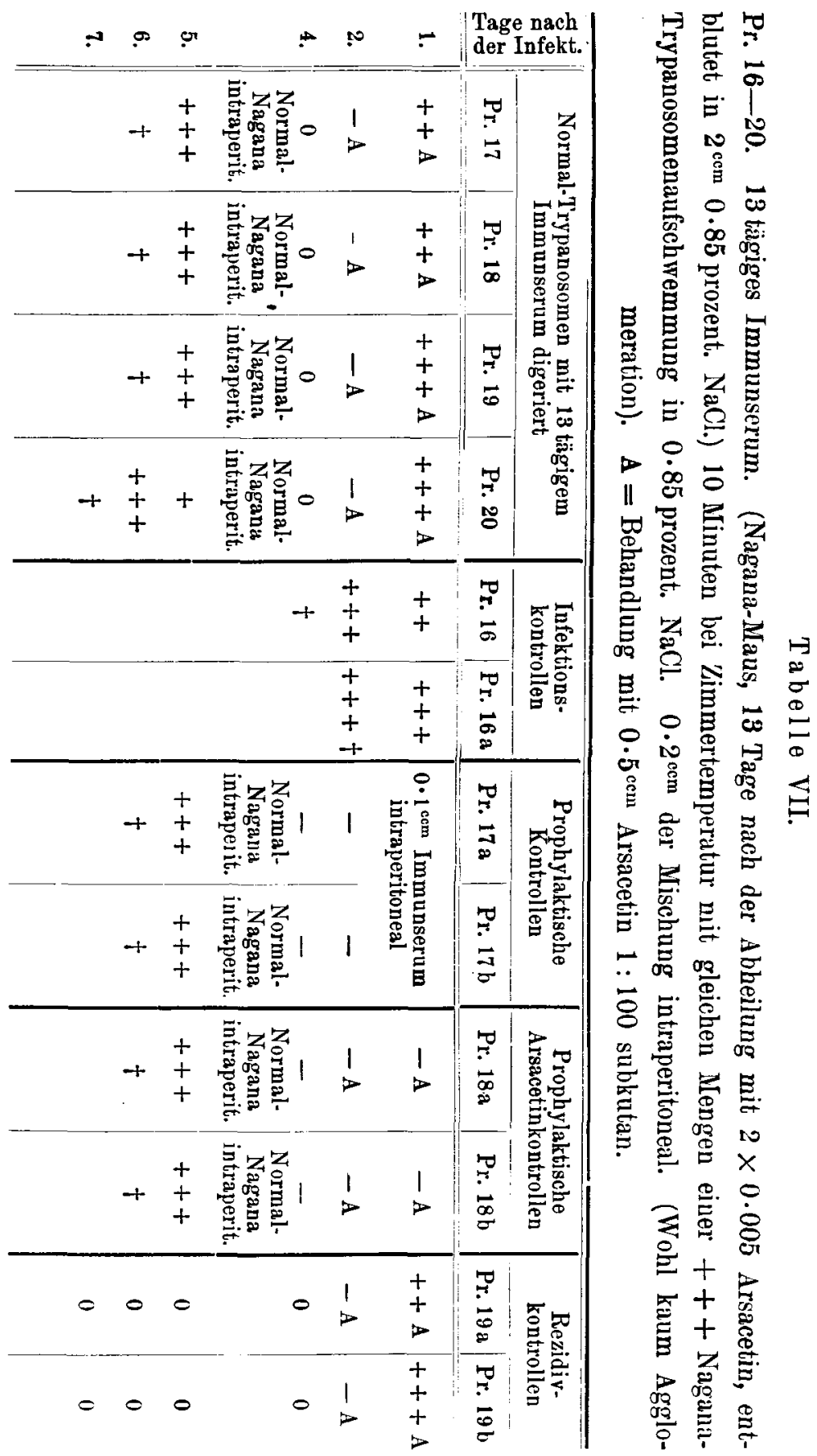


Im Laufe der Passagen konnten wir bei diesem Stamm eine Rückverwandlung in den Ausgangsstamm beobachten, die wir in ihren verschiedenen Etappen verfolgen konnten und über die wir weiter unten noch ausführlich berichten werden (vgl. S. 525).

Ziehen wir das Fazit aus unseren bisherigen Untersuchungen, so geht aus ihnen hervor, daB es in Ubereinstimmung mit den wichtigen Angaben Ehrlichs, Röhls und Gulbransens bei Anwendung zwei- bis vieltägiger Trypanosomenimmunsera gelingt, durch Behandlung von Trypanosomen im Reagensglase mit spezifischem Serum die Trypanosomen so zu verändern, daB sie sich im Tierkörper als Träger von Rezidirstammeigenschaften entwickeln. Ein Parallelismus zwischen dem trypanoziden Titer eines spezifischen Immunserums und seiner Fähigkeit, die Normalindividuen in den Zustand der Rezidivparasiten hinüberzuführen, besteht jedoch nicht.

Die in den vorangehenden Experimenten gewählte Versuchsmethodik gewährt nur einen beschränkten Einblick in die biologischen Prozesse, wie sie sich in den der spezifischen Serumwirkung im Reagensglase ausgesetzten Parasiten vollziehen. Wir sind in diesen Versuchen ja so vorgegangen, daB wir die biologischen Qualitäten der mit Immunserum behandelten, im Tierkörper sich entwickelnden Trypanosomen mit Hilfe der an die chemotherapeutische Abheilung der Infektion sich anschlieBenden Nachinfektion mit dem Normal-Ausgangsstamm prüften. Ging diese Infektion an, so war damit die Umwandlung des vorgeimpften Stammes zum Rezidivstamm gegeben. Versagte dagegen die Nachinfektion des normalen Ausgangsstammes, so wurde hieraus geschlossen, daB der Umschlag des Ausgangsstammes zum Rezidirstamm trotz des Kontaktes mit dem Serum der abgeheilten Tiere unterblieben war. Es ist nun klar, daB derartige Schlüsse nur unter der Voraussetzung ihre Gültigkeit besitzen, daB im Experiment die in Betracht kommenden Extreme erfüllt sind, daB nämlich entweder die Umwandlung des Ausgangsstammes zum Rezidirstamm oder das Ausbleiben dieses Umwandlungsprozesses alle Individuen gleichmäßig betrifft. Auf die zwischen diesen Extremen liegenden experimentellen Möglichkeiten läßt jedoch die bisherige Versuchsanordnung keine Rückschlüsse zu. Nehmen wir z. B. an, wofür noch der experimentelle Beweis zu erbringen sein wird, daB der Umschlag der Ausgangsparasiten zu Rezidivtrypanosomen dank den zwischen den einzelnen Parasiten bestehenden individuellen Differenzen sich nicht in allen Individuen des betreffenden Stammes gleichmäBig vollzieht, daß trotz des Serumkontaktes nur ein Teil der Ausgangstrypanosomen Rezidivstammeigenschaften annimmt, ein anderer der Umwandlung nicht unterliegt, so entstehen bei 
der Abheilung eines solchen Mischstammes Antikörper, die zum Teil gegen den entstandenen Rezidivstamm, zum Teil aber auch gegen den Ausgangsstamm gerichtet sind. Die Folge hierron dürfte sein, daB die Nachinfektion mit dem Ausgangsstamm nicht angeht, obwohl eine gewisse Zahl ron Individuen unter dem EinfluB des spezifischen Serums eine biologische Konstitutionsänderung in der Richtung des Rezidivstammes erfahren hat. In allen unseren bisherigen Versuchen, in denen sich die Nachinfektion mit Normal-Nagana als erfolglos erweist, ist somit im Grunde genommen nur die Schlubfolgerung berechtigt, daB trotz starker Trypanozidie des betreffenden Serums bei einer nicht unbeträchtlichen Menge von Individuen eine Umwandlung zu Individuen mit Rezidivstammeigenschaften ausbleiben kann. $\mathrm{Ob}$ nicht daneben bei anderen Individuen des gleichen Ausgangsstammes die Umprägung zum Rezidirparasit unter Serumkontakt doch stattfindet, muB unter der bisherigen Methodik in suspenso gelassen werden.

Um diese Lücke in unseren Versuchen zu füllen, wurden die folgenden Experimente unternommen. Die ausführliche Schilderung derselben gibt zugleich einen Überblick über die angewandte Versuchsmethodik.

\section{Versuch VIII.}

Pr. 153a. Nagana-Naus, 8 Tage nach der Abheilung mit 2 mal 0.5 Arsacetin $1: 100$, wird in $2^{\mathrm{ccm}} 0.85$ prozent. $\mathrm{NaCl}$-Lösung entblutet. $0.5 \mathrm{~cm}$ dieser Blutsuspension werden mit $0.5 \mathrm{~cm}$ einer +++ -Normal-Naganaaufschwemmung in 0.85 prozent. $\mathrm{NaCl}-$ Lösung 15 Minuten bei Zimmertemperatur digeriert. Hierauf werden $0.2^{\mathrm{cm}}$ der Mischung einer normalen Maus Pr. 153 a intraperitoneal injiziert.

Tabelle VIIIa.

$\mathrm{A}=$ Bebandlung mit $0.5^{\mathrm{cm}}$ Arsacetin $1: 100$ subkutan.

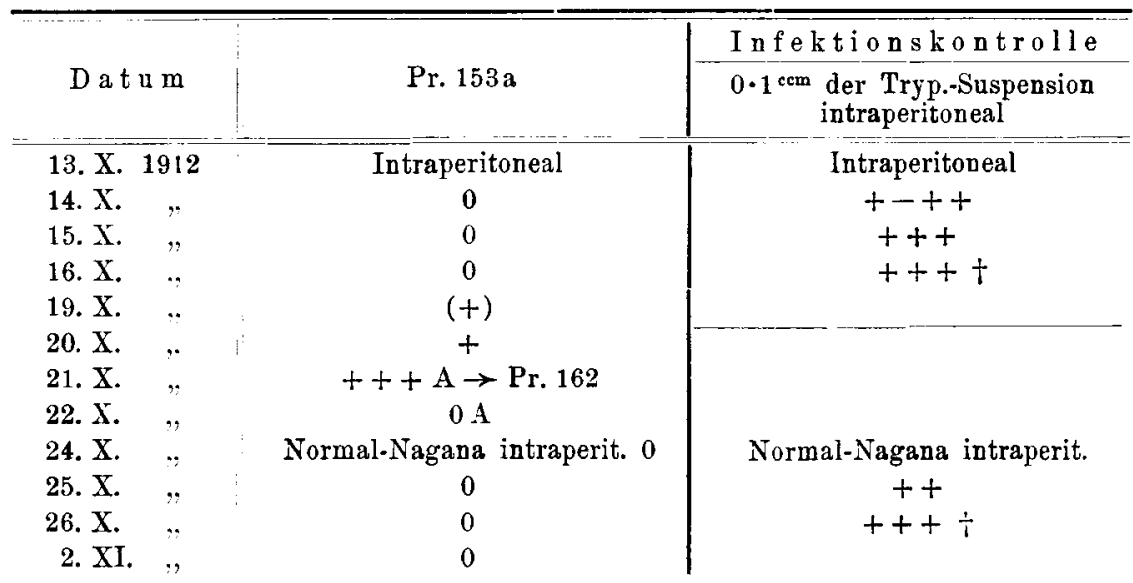


Wie die Tabelle zeigt, geht der mit dem 8 tägigen Immunserum digerierte Normalstamm unter sehr erheblicher Verzögerung gegenüber den Infektionskontrollen an. Während diese bereits am 16.X. 12 der Infektion erlegen sind, treten erst 3 Tage später, am 19.X.12 die Trypanosomen bei Pr. 153a spärlich in der Zirkulation auf. Am 21.X.12 befindet sich die Maus auf der Höhe der Infektion. Kurz vor der chemotherapeutischen Abheilung mit $0.5 \mathrm{~cm}$ Arsacetin 1:100 subkutan, einer Dosis, die auch am 22. X. 12 zum Zwecke einer sicheren Heilung wiederholt wird, wird der Stamm auf die Normal-Maus Pr. 162 überimpft und dann auf inzwischen vorbereitete, mit Normal-Nagana infizierte und mit Arsacetin abgeheilte Mäuse am 24.X.12, an dem die Maus Pr. 162 einen reichlichen Trypanosomengehalt im Blut besitzt, intraperitoneal übertragen (Tabelle VIIIc, Pr. 171 bis 173).

Tabelle VIIIb.

Pr. 162. Subk. v. Pr. 153.

\begin{tabular}{c|c}
\hline Datu & Subkutane Infektion \\
\hline \hline 21. X. 1912 & - \\
23. X. " & + \\
24. X. $"$ & +++ \\
&
\end{tabular}

Wir prüfen somit das biologische Verhalten des mit Immunserum digerierten Normal-Stammes in diesem Versuche wie in den beiden folgenden Experimenten mit Hilfe von zwei Immunitätsreaktionen: 1. mit der bisher angewandten Methode, indem wir den der spezifischen Serumwirkung ausgesetzten Normal-Stamm im Mauskörper abtöten und Normal-Stamm nachimpfen (vgl. Pr. 153a) und 2. dadurch, daB wir den unter Serumkontakt gewesenen Ausgangsstamm bei vollentwickelter Infektion auf Mäuse übertragen, die, mit dem Ausgangsstamm rorgeimpft, bei beträchtlichem Trypanosomengehalt des Blutes abgeheilt worden waren (vgl. Pr. 171 bis 172). Die letztere Methode, bei der in gleícher Weise die charakteristischen biologischen Differenzen zwischen Ausgangsstamm und Rezidivstamm in die Erscheinung treten müssen, hat den Vorteil, das selbst vereinzelte Rezidivparasiten, einer größeren Menge von Normal-Individuen beigemengt, der Beobachtung im Experiment nicht entgehen können, da die bei der Abheilung des Normalstammes entstehenden spezifischen Antikörper ihnen gegenüber wirkungslos bleiben. Sie erfahren auf diese Art gewissermaBen ein en Filtrationsproze8, durch welchen sie von den ihnen beigejnischten 
Normal-Individuen mit den Eigenschaften des Ausgangsstammes gereinigt werden. Versagt also bei Vorinfektion und Abheilung des Ausgangsstammes die Nachinfektion des im Reagensglase mit Immunserum behandelten Stammes, so ist mithin der SchluB gerechtfertigt, daB sämtliche Individuen dieses Stammes trotz des Serumkontaktes in vitro ihre NormalStammeigenschaften bewahrt haben. Dies trifft auch in der Tat für den im Versuch VIII mit 8 tägigem Immunserum in vitro digerierten NormalStamm zu. Seine Abheilung in VIIIa verhindert das Angehen der Nachinfektion mit Normal-Nagana, ebenso vermag auch in VIIIc die Abheilung der Vorinfektion mit Normal-Nagana die Versuchstiere Pr. 171 und 172 vor einer neuen Infektion mit dem der Serumwirkung in vitro ausgesetzten Stamme zu schützen.

Tabelle VIIIc.

\begin{tabular}{|c|c|c|c|}
\hline \multirow[b]{2}{*}{ Datum } & \multicolumn{3}{|c|}{ Intraperitoneale Infektion } \\
\hline & Pr. 171 & Pr. 172 & $\begin{array}{c}\text { Infektionskontrolle } \\
\text { Pr. } 173 \\
\end{array}$ \\
\hline 18. X. 1912 & Normal-Nagana & Normal-Nagana & 一 \\
\hline 20. X. & $++\mathbf{A}$ & $++A$ & $-\mathrm{A}$ \\
\hline 21. X. & $\mathbf{A}$ & A & $-A$ \\
\hline 24. X. & 0 Pr. 162 & 0 Pr. 162 & Pr. 162 \\
\hline 25. X. & 0 & 0 & + \\
\hline 26. X. & 0 & 0 & +++ \\
\hline 27. X. & 0 & 0 & + \\
\hline 29. X. & 0 & $0+$ & \\
\hline 2. XI. , & 0 & $\begin{array}{c}\text { Im Herzblut keine } \\
\text { Trypanosomen }\end{array}$ & \\
\hline
\end{tabular}

Das gleiche Ergebnis weist der folgende Versuch IX auf, bei dem unter gleicher Versuchsmethodik ein 12 tägiges Immunserum zur Verwendung gelangte.

\section{Versuch IX.}

Pr. 159a und Pr. 159b. Nagana-Maus, 12 Tage nach der Abheilung mit 2 mal 0.5 Arsacetin $1: 100$, wird in $2 \mathrm{ccm} 0.85$ prozent. NaCl-Lösung entblutet. $0.5^{\mathrm{cem}}$ dieser Blutsuspension werden mit $0.5^{\mathrm{cm}}$ einer +++Normal-Naganaaufschwemmung in 0.85 prozent. NaCl-Lösung 15 Minuten bei Zimmertemperatur digeriert. Hierauf $0.2 \mathrm{cem}$ der Mischung intraperitoneal bei Maus Pr. 159a und b. A = Behandlung mit 0.5 $\mathrm{cm}$ Arsacetin 1:100 subkutan. 
Genese Des Rezidivs B. D. experim. Trypanosomeninfektion. 509 Tabelle IXa.

\begin{tabular}{|c|c|c|c|c|}
\hline \multirow{2}{*}{ Datam } & \multirow{2}{*}{ Pr. $159 \mathrm{a}$} & \multirow{2}{*}{ Pr. $159 \mathrm{~b}$} & \multicolumn{2}{|c|}{ Infektionskontrolle } \\
\hline & & & Pr. 161 & Pr. $167 \mathrm{a}$ \\
\hline 17. X. 191 & Intraperitoneal & Intraperitoneal & $\begin{array}{l}\text { 0.1 Tryp.-Auf- } \\
\text { schwemmung } \\
\text { intraperitoneal }\end{array}$ & - \\
\hline 18. X. & 0 & 0 & ++ & - \\
\hline 19. $X$. & 0 & 0 & $t+t+$ & - \\
\hline 21. X. & 0 & 0 & & - \\
\hline 22. X. & $(+) \rightarrow \operatorname{Pr} 166$ & $(t)$ & & - \\
\hline 23. X. & $++A$ & $++A$ & & $-A$ \\
\hline 24. X. " & A & A & & $-\mathbf{A}$ \\
\hline 26. X. & $\begin{array}{l}\text { Normal-Nagana } \\
\text { intraperitoneal }\end{array}$ & $\begin{array}{l}\text { Normal-Nagana } \\
\text { intraperitoneal }\end{array}$ & & $\begin{array}{l}\text { Normal-Nagana } \\
\text { intraperitoneal }\end{array}$ \\
\hline 27. $x$. & 0 & 0 & & ++ \\
\hline 28. X. & 0 & 0 & & $t+t+$ \\
\hline 6. XI. " & 0 & $\mathbf{0}$ & & \\
\hline
\end{tabular}

Auch hier entwickeln sich die in vitro mit dem Immunserum digerierten Trypanosomen erheblich verspätet gegenüber den Kontrollen, und das Versagen der Nachinfektion mit Normal-Nagana zeigt, daB zum mindesten ein großer Teil der Normal-Parasiten trotz des Serumkontaktes im Reagensglase die Eigenschaften des Ausgangsstammes bewahrt hat (Pr. 159a und b). DaB trotz der ausgesprochenen Trypanozidie des verwendeten Serums auch nicht einmal in vereinzelten Individuen sich ein Umschlag in der Richtung des Rezidivstammes vollzogen hat, beweist alsdann die im Versuch VIII eingehend geschilderte Versuchsanordnung. Wir haben am 22. X. 12, als bei Pr. 159a die ersten Trypanosomen in der Zirkulation erschienen, etwas Schwanzblut auf Pr. 166 übertragen und am 24.X. 12 die im Blut reichlich vorhandenen Trypanosomen auf die mit Normal-Nagana vorinfizierten und dann abgeheilten Mäuse Pr. 173 bis 174 und auf die Infektionskontrolle Pr. 175 intraperitoneal überimpft (siehe Versuch IX $b$ und IXc).

Tabelle IXb.

Pr. 166. Überimpft von Pr. 159 a.

\begin{tabular}{l|l}
\hline Datum & Intraperitoneale Infektion \\
\hline $\begin{array}{l}\text { 22. X. } 1912 \\
\text { 24. X. } .,\end{array}$ & ++ Überimpft auf Pr. 173-175
\end{tabular}


Diese Nachinfektion geht bei Pr. 173 und 174 nicht an, beide Tiere sind noch nach 12 Tagen am 5.XI. 12 trypanosomenfrei, obwohl die gleiche Infektion bei dem nicht vorinfizierten Tiere Pr. 175 innerhalb von 3 Tagen zum Tode geführt hat. DaB nicht etwa eine prophylaktische Wirkung des zur Abheilung am 21. und 22.X. 12 benutzten Arsacetins interferiert, zeigt die gleiche Kontrolle Pr. 175, deren 2 malige Vorbehandlung mit $\mathbf{0 . 5}$ Arsacetin 1:100 subkutan ohne Einflub auf die am 24. X.12 erfolgende Nachinfektion mit Pr. 166 bleibt. Es liefert somit der Ausfall dieses Versuches IX ebenso wie Versuch VIII einen erneuten Beweis, daB trotz starker Trypanozidie des Immunserums eine Umwandlung der Normal-Parasiten zu Rezidivparasiten völlig ausbleiben kann, und daB der trypanozide Titer eines spezifischen Trypanosomenimmunserums und die rezidirstammbildenden Funlitionen des gleichen Serums in keinem Verhältnis zueinander stehen.

Tabelle IXc.

\begin{tabular}{|c|c|c|c|}
\hline \multirow{3}{*}{ Lat $\mathbf{u} \mathbf{m}$} & \multicolumn{3}{|c|}{ Intraperitonea le Infektion } \\
\hline & Pr 179a & $P_{r} 174$ & Kontrolle \\
\hline & & & Pr. 175 \\
\hline 18. X. 1912 & Normal-Nagana & Normal-Nagana & - \\
\hline 21. X. , , & $+++A$ & $+++A$ & $-A$ \\
\hline 22. X. , , & A & A & $-\mathbf{A}$ \\
\hline 24. X. , , & Intraperit. von Pr. 166 & Intraperit. von Pr. 166 & Intraperit. von Pr. 166 \\
\hline 25. X. " , & 0 & 0 & + \\
\hline 26. X. $"$, & 0 & 0 & ++ \\
\hline 27. X. $"$ & 0 & 0 & $+t+t$ \\
\hline 31.X. " , & 0 & 0 & \\
\hline 5. XI. , & 0 & 0 & \\
\hline
\end{tabular}

Nicht in allen Versuchen, in denen sich die Nachinfektion mit Normal-Nagana nach Abheilung der Infektion des mit Immunserum in vitro behandelten Ausgangsstammes als erfolglos erwies, hatten wir das gleiche Resultat zu verzeichnen, daB trotz Kontaktes der Trypanosomen mit einem stark trypanoziden Immunserum in vitro sämtliche Individuen vor der Umwandlung in Rezidivparasiten verschont blieben. So konnten wir in einem Versuche, dessen Protokoll wir im folgenden wiedergeben, beobachten, daß der nach Digerierung mit einem 12 tägigen Immunserum im Nauskörper angehende Stamm Normal-Stamm- und Rezidivstammeigenschaften gleichzeitig aufwies. 


\section{Versuch Xa.}

Pr. 160. Nagana-Maus, 12 Tage nach der Abheilung, mit $2 \mathrm{mal} 0 \cdot 5 \mathrm{~cm}$ Arsacetin $1: 100$ subk., entblutet in $2^{\mathrm{cm}} 0.85$ prozent. $\mathrm{NaCl}$-Lösung. $0.3^{\mathrm{cm}}$ dieser Aufschwemmung werden mit $0.5^{\mathrm{cm}}$ einer +++ -Normal-Trypanosomenaufschwemmung in 0.85 prozent. NaCl-Lösung 15 Minuten bei Zimmertemperatur digeriert. Hierron $0.2^{\mathrm{cm}}$ intraperitoneal. $\mathbf{A}=$ Behandlung mit Arsacetin $0.5^{\mathrm{ccm}} 1: 100$ subk.

Tabelle $\mathrm{X}$ a.

\begin{tabular}{|c|c|c|}
\hline \multirow{2}{*}{ Datum } & \multirow{2}{*}{ Pr. 160} & Infektionskontrolle \\
\hline & & Pr. 161 \\
\hline $\begin{array}{l}\text { 17. X. } 1912 \\
\text { 18. X. " } \\
\text { 19. X. " } \\
\text { 20.X. " } \\
\text { 21. X. " }\end{array}$ & $\begin{array}{c}\text { Intraperitoneal } \\
0 \\
0 \\
(+) \\
++\rightarrow \text { Pr. } 164-165\end{array}$ & $\begin{array}{c}0.1 \text { cem Tryp.-Aufschwemmung intraperit. } \\
++ \\
+++t\end{array}$ \\
\hline
\end{tabular}

Dieser, gegenüber der Infektionskontrolle Pr. 161 sich deutlich rerzögert entwickelnde Stamm Pr. 160 wurde am 21.X.12 auf die Mäuse Pr. 164 und 165 intraperitoneal übertragen, und nach seiner Abheilung die Immunität der Tiere gegenüber dem Normal-Stamm geprüft. Es blieb die Nachinfektion mit Normal-Nagana erfolglos, der mit Immunserum in vitro behandelte Stamm setzte sich also aus Parasiten vom Typus des Ausgangsstammes zusammen. Wurde nun umgekehrt bei Pr. 168 und 169 Normal-Nagana rorinfiziert und der Stamm Pr. 164, der die erste Passage des mit Immunserum im Reagensglase behandelten Normal-Stammes Pr. 160 darstellt, nachinfiziert, so ging die Infektion an, ein Beweis, daB der in vitro der Immunserumwirkung ausgesetzte NormalStamm im Tierkörper gleichzeitig als Träger von Rezidivstammeigenschaften auftritt (siehe Versuch $\mathrm{Xc}$ ).

Tabelle Xb.

Uberimpft von Pr. 160.

\begin{tabular}{|c|c|c|c|}
\hline Dat u m & $\operatorname{Pr}, 164$ & Pr. 165 & Infektionskontrolle \\
\hline 21. X. 1912 & Intraperitoneal & Intraperitoneal & 一 \\
\hline 23. X. $"$, & $++\mathrm{A} \rightarrow \operatorname{Pr} .168-170$ & $++A$ & $A$ \\
\hline 24. X. " & $-\mathrm{A}$ & $-\mathbf{A}$ & A \\
\hline 27. X. & $\begin{array}{c}0 \text { Normal-Nagana } \\
\text { intraperitoneal }\end{array}$ & $\begin{array}{l}0 \text { Normal-Nagana } \\
\text { intraperitoneal }\end{array}$ & $\begin{array}{l}\text { Normal-Nagana } \\
\text { intraperitoneal }\end{array}$ \\
\hline 28. X. & 0 & 0 & ++ \\
\hline 29. X. " , & 0 & 0 & $+++\div$ \\
\hline 31. X. & 0 & 0 & \\
\hline 3. XI. .. & 0 & 0 & \\
\hline
\end{tabular}


Tabelle Xc.

Pr. 168 und Pr. 169. Vorgeimpft Normal-Nagana.

\begin{tabular}{|c|c|c|c|}
\hline \multirow{2}{*}{ Dat u m } & \multirow{2}{*}{ Pr. 168} & \multirow{2}{*}{ Pr. 169} & Infektionskontrolle \\
\hline & & & Pr. 170 \\
\hline 18. X. 1912 & $\begin{array}{l}\text { Normal-Nagana } \\
\text { intraperitoneal }\end{array}$ & $\begin{array}{c}\text { Normal-Nagada } \\
\text { intraperitoneal }\end{array}$ & - \\
\hline 20. X. , , & $++A$ & $++A$ & $-A$ \\
\hline 21. X. , , & $-A$ & $-\mathrm{A}$ & $-A$ \\
\hline 23. X. & 0 Intraperit. Pr. 164 & 0 Intraperit. Pr. 164 & Intraperit. Pr. 164 \\
\hline 24. X. & 0 & $(t)$ & $(+)$ \\
\hline 25. X. , , & $(t)$ & $(+)-+$ & + \\
\hline 26. X. , , & ++ & $++\rightarrow$ Pr. $182-183$ & +++ \\
\hline 27. X. & $++t+$ & $+t+t$ & $t$ \\
\hline
\end{tabular}

Wir können somit in Ergänzung unserer Versuche I bis VIII folgende Resultate fixieren:

Aus Versuch VIII bis $\mathrm{X}$ geht hervor, daB die Behandlung von Normal-Trypanosomen im Reagensglase mit stark trypanozidem Immunserum in zahlreichen Fällen ohne jeden EinfluB auf die biologische Struktur sämtlicher Parasiten bleibt, die sich im Tierkörper wieder als Ausgangsstammindividuen entwickeln. Iu manchen Fällen (z. B. Versuch $X$ ) ist jedoch damit zu rechnen, daB unter dem Einflusse des Immunserumkontaktes nicht eine totale Umwandlung des A usgangsstammes zum Rezidivstamm eintritt, sondern der sich entwickelnde Stamm Normal-Stamm- und Rezidirstammeigenschaften in sich vereinigt, wobei die Frage offen gelassen werden muB, ob es sich um eine Population von Normal- und Rezidirindividuen hierbei handelt, oder die einzelnen Parasiten über zwei dominante Rezeptorenapparate rom Typus des Normal- und Rezidir. stammes gleichzeitig verfügen.

Es ergänzen sich somit unsere sämtlichen Versuche zu dem einheitlichen Resultat, dab das trypanozide Vermögen eines spezifischen Trypanosomenimmunserums nicht den bestimmenden Faktor für den Umschlag des Ausgangsstammes zum Rezidirstamm darstellt und dab Trypanozidie und Rezidirstammbildungsvermögen eines Immunserums in keinem Abhāngigkeitsverhältnis zueinander sich befinden.

Aus dieser Unabhängigkeit der beiden Serumeigenschaften voneinander ergibt sich aber weiter die für das Verständnis der Genese des Rezidivs wichtige Konsequenz, daB Trypanozidie und Rezidivstammbildungsvermögen nicht Funktionen eines einzigen Serumsubstrates sind, sondern 
mit großer Wahrscheinlichkeit Eigensehaften wesensdifferenter Serumkörper darstellen.

Mit dieser Annahme der Verschiedenheit zwischen den trypanoziden Substanzen des Immunserums und den den Rezidivstamm auslösenden Serumkomponenten, die wir im folgenden kurz als "Rezidivkörper" bezeichnen, wäre die Dissonanz zwischen den trypanoziden Kräften und den rezidivstammbildenden Eigenschaften der Trypanosomenimmunsera, wie wir sie im Verlauf unserer Reagensglasversuche so häufig beobachten konnten, ohne weiteres erklärt.

Unter den eben entwickelten Gesichtspunkten stellen wir uns nun vor, dab sowohl bei der spontanen wie chemotherapeutischen Heilung der experimentellen Trypanosomeninfektion folgende zwei Arten von Immunkörpern entstehen:

1. Solche, welche dank ihrer Verwandtschaft zum dominanten Rezeptorenapparat sich an diesem verankern, von dort aus die Trypanosomen angreifen und je nach der Intensität ihrer Einwirkung sie schädigen, bzw. töten. ${ }^{1}$

2. Rezidivkörper, d. h. immunisatorisch ausgelöste Serumkörper, auf deren Reiz hin die Trypanosomen zur Ausbildung eines neuen, vom Ausgangsstamm verschiedenen dominanten Rezeptorenapparates gedrängt werden.

In Konsequenz der eben entwickelten Anschauung von der Wesensdifferenz zwischen trypanoziden Immunkörpern und Rezidivkörpern sind wir nun in den folgenden Cntersuchungen dazu übergegangen, unsere Annahme von der Sonderexistenz dieser beiden Körper durch weitere experimentelle Befunde zu stützen. Wir sind uns bewuBt, daB die in dieser Richtung unternommenen Versuche keinen AbschluB und keine endgültige Beantwortung der ron uns angeschnittenen Frage bedeuten, sind aber der Ansicht, daB sie weitere Argumente zugunsten unserer Vorstellang liefern, daB die Umwandlung des Ausgangsstammes zum Rezidirstamm nicht allein unter dem EinfluB trypanozider Antikörper, sondern unter Mitbeteiligung anderer selbständiger Serumsubstrate, der von uns als "Rezidivkörper" bezeichneten Körper sich volizieht.

1 A nmerkung: DaB serumfeste Stämme, ohne Rezidivstammeigenschaften erlangt zu haben, also ohne die Ausbildung neuer dominanter Rezeptoren durchaus existenzfähig sein können, haben kürzlich Braun und Teichmann an dem Beispiel eines „Rinderserum-festen Stammes“ gezeigt, der, ohne antigene Eigenschaften gegen seine eigenen und gegen den primären Stamm in der Maus za besitzen, doch in seiner Wachstumsenergie in Mäusen in keiner Weise hinter dem Ausgangsstamm zurückblieb.

Zeitschr. f. Hygiene. LXXIV 
So können wir im folgenden über Versuche berichten, in denen es gelungen ist, durch Erwärmen eines Trypanosomen-Immunserums während 15 Minuten auf $60^{\circ}$ im Wasserbade die rezidivstammbildenden Ejgenschaften des Serums zu zerstören, ohne daB die trypanoziden Eigenschaften des Immunserums dadurch eine EinbuBe erlitten. Bekanntlich widersteht - wir verweisen z. B. auf die Untersuchungen von Laveran und Mesnil über das trypanozide Vermögen des Serums von mit Trypanosoma Lewisi infizierten Ratten die Trypanozidie eines spezifischen Trypanosomen-Immunserums der Erhitzung auf $58-64^{\circ} \mathrm{C}$ bis zu $9 / 4$ Stunden. Es verliert hierbei nur einen Teil seiner Wirksamkeit, während eine gleichdauernde Erwärmung auf $70^{\circ}$ im allgemeinen die trypanoziden Immunsubstanzen des Serums zerstört.

Das gleiche trifft auch nach unseren Versuchsergebnissen bei Erhitzung auf $70^{\circ} \mathrm{C}$ für die rezidivstammbildenden Subtrate des Serums zu, wie dies aus dem folgenden Beispiel herrorgeht (rgl. S. 515).

In diesem Versuche XI wurde eine Normal-Naganamaus, 4 Tage nach der Abheilung mit 2 mal 0.005 Arsacetin subkutan, in $3 \mathrm{~cm} 0.85$ prozent. Kochsalzlösung entblutet. $1.5^{\mathrm{cem}}$ der Blutaufschwemmung wurden nun 15 Minuten im Wasserbade bei $70^{\circ}$ gehalten und hierauf nach Abkühlung unter fließendem Wasser, in absteigenden Mengen mit $0.5^{\mathrm{ccm}}$ einer +++- Normal-Trypanosomenaufschwemmung im Reagenzglase digeriert, wobei entsprechend der größten im Versuch verwendeten Immunserummenge sämtliche Röhrchen vor dem Trypanosomenzusatze mit physiologischer Kochsalzlösung auf $0.5^{\mathrm{ccm}}$ aufgefüllt wurden. Das gleiche geschah mit der nicht erhitzten nativen Immunserummenge. Nach 15 Minuten wurden alsdann $0.2^{\mathrm{cm}}$ aus jedem Reagenzglase je einer Maus intraperitoneal injiziert. Den Verlauf des Versuches gibt die folgende Tabelle wieder (Tabelle XI).

Wir sehen zunächst bei den mit natirem Serum in vitro behandelten Tryponosomen eine deutliche Verzögerung der Infeltion, die erst am 5. Infektionstage zu einem spärlichen Erscheinen der Trypanosomen in der Zirkulation führt (Pr. 99, 101, 103), während die Infektionskontrollen bereits am 3. Versuchstage ihrer Infektion erlegen sind (Pr. 100a und 100 b). Wie das Angehen der Nachinfektion mit Normal-Nagana am 12. Versuchstage demonstriert, haben sich die in vitro mit dem 4 tägigen Immunserum digerierten Normal-Parasiten im Mauskörper als Träger ron Rezidivstammeigenschaften entwickelt, da ihre Abheilung keine Immunität gegen die Ausgangsparasiten herbeiführt. Die Erhitzung des gleichen Immunserums auf $70^{\circ}$ während 15 Minuten rernichtet dagegen die trypanozide wie diè rezidirstammbildenden Eigenschaften des Serums. Die mit dem 
Genese des Rezidivs B. D. Experim. Trypanosomeninfektion. 515

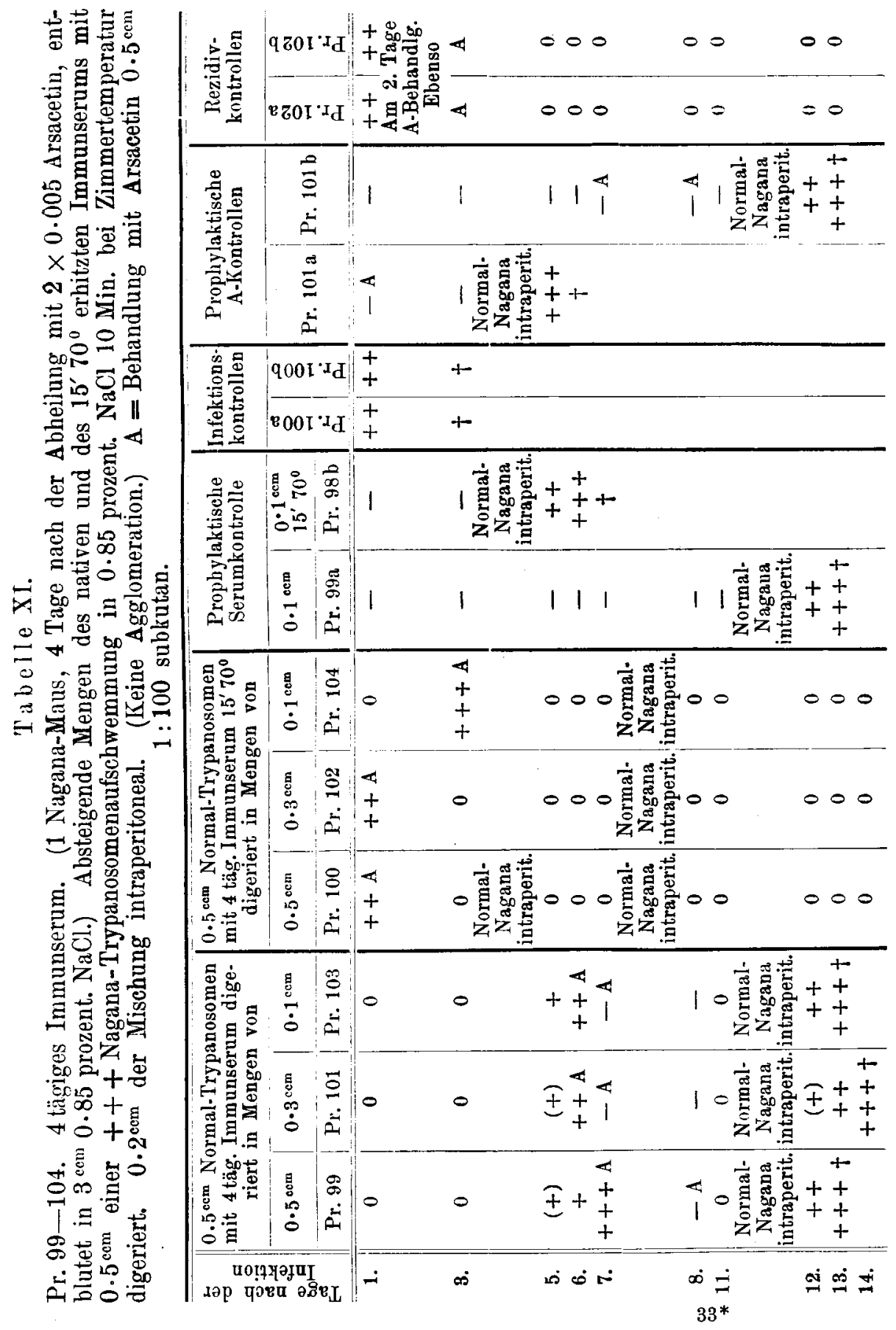




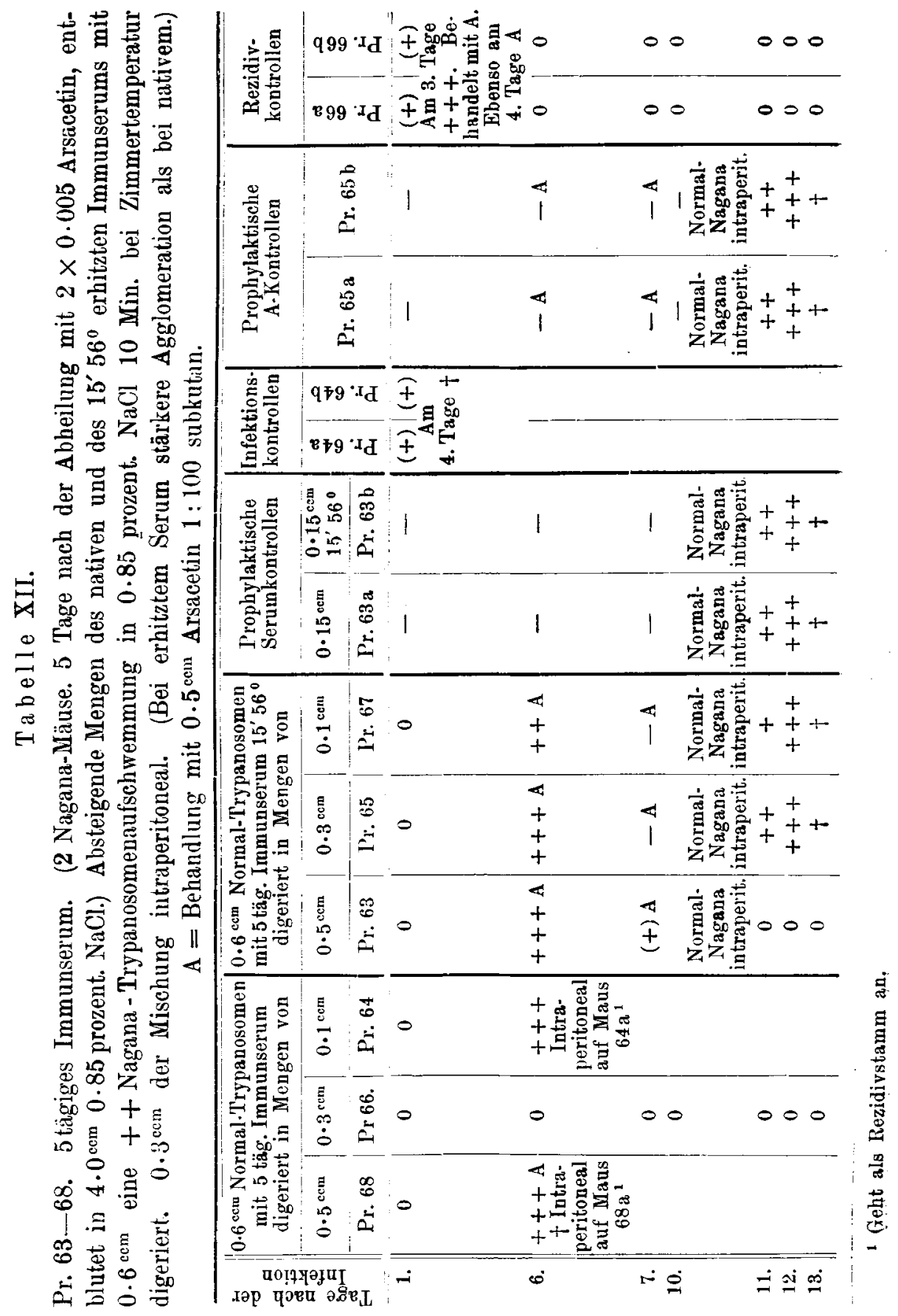


erhitzten Serum im Reagensglase digerierten Trypanosomen entwickeln sich ebenso rasch wie die unberührt gebliebenen Parasiten der Infektionskontrollen und bewahren auch die biologischen Eigenschaften des Ausgangsstammes, wie das Ausbleiben der Nachinfektion mit Normal-Nagana nach Abheilung der Infektion durch Arsacetin anzeigt. Nur bei Pr. 104 macht sich noch eine geringe Trypanozidie des auf $70^{\circ}$ erhitzten Serums bemerkbar.

Die erste Andeutung einer verschiedenen Thermoresistenz der trypanoziden Immunsubstanzen und der Rezidivkörper erhielten wir, als wir ein 5 tägiges Immunserum 15 Minuten einer Erwärmung auf $56^{\circ}$ aussetzten (vgl. Tabelle XII).

Während bei Pr. 64 und 68 bei ausgesprochener Trypanozidie des nativen Immunserums die unter deutlicher Verzögerung angehenden Trypanosomen unter dem Einflusse des Immunserums sich zu Rezidiv-Parasiten umgewandelt haben - bezüglich Einzelheiten verweisen wir auf unsere Ausführungen bei Versuch IVa und IVb, der, soweit natives Immunserum im Reagenstersuch verwandt wurde, dieser Tabelle entlehnt ist - , ergibt sich bei Benutzung des gleichen, aber $15^{\prime}$ auf $56^{\circ}$ erhitzten Immunserums ein etwas verändertes Bild. Bei Pr. 65 und Pr. 67 ist die Erwärmung des Immunserums anscheinend ohne Einfluß geblieben. Wenigstens geht die Infektion der mit dem erhitzten Immunserum in vitro digerierten Trypanosomen unter gleicher Verzögerung an wie bei Pr. 64 und 68, und auch die rezidivstammbildenden Funktionen des Serums haben unter der thermischen Einwirkung keine wesentliche EinbuBe erlitten, da, wie die erfolgreiche Nachinfektion mit Normal-Nagana bei P. 65 und Pr. 67 anzeigt, die mit dem erhitzten Immunserum behandelten Trypanosomen Rezidivstammeigenschaften angenommen haben. Dagegen ist bei Pr. 63 trotz anscheinend gleicher Trypanozidie des Immunserums wie bei Pr. 65 und Pr. 67 - die Infektion zeigt sich gleichfalls erst am 6. Versuchstage in voller Entwicklung - das rezidirstammbildende Vermögen des erwärmten Immunserums erloschen. Die nach der chemotherapeutischen Behandlung nachgeschickte Infektion mit Normal-Nagana geht nicht an, die mit dem auf $60^{\circ}$ erwärmten Immunserum im Reagensglase gemischten Trypanosomen bewahren ihre Normalstammeigenschaften, obwohl die trypanozide Kraft des erhitzten Immunserums entsprechend seiner unverändert gebliebenen prophylaktischen Wirkung nicht gelitten hat. Diese Beobachtung, die den SchluB nahelegte, daB die rezidivstammbildenden Substrate des Trypanosomen-Immunserums thermolabiler als die trypanoziden Immunkörper seien, ließ uns weiter folgern, daß vielleicht die Erwärmung des Immunserums während 15 Minuten auf $56^{\circ}$ kein Temperaturoptimum darstelle, und daß sich bei höheren Wärmegraden mög- 
licherweise eklatantere Ausschläge im Sinne einer verschiedenen Thermoresistenz der trypanoziden Serumkörper und der Rezidivkörper ergeben würden.

In der Tat ist es uns, wie das folgende Versuchsbeispiel zeigt, gelungen, durch Erhitzen eines 8tägigen Immunserums während 15 Minuten auf $60^{\circ}$ im Wasserbade das Immunserum elektiv seiner rezidivstammbildenden Funktion ohne Schädigung seiner trypanoziden Eigenschaften zu berauben (vgl. Tabelle XIII).

Der mit dem Immunserum im Reagensglase behandelte Normalstamm geht in Pr. 111 und 112 unter geringer Verzögerung gegenüber den Infektionskontrollen Pr. $112 \mathrm{a}$ und Pr. $112 \mathrm{~b}$ als typischer Rezidivstamm an: Die an seine Abheilung sich anschlieBende Immunität vermag die Tiere nicht vor einer Nachinfektion mit dem Normalstamm zu schützen, der sich, wie in der Kontrolle Pr. 111a, ungehemmt entwickelt und innerhalb von 3 Tagen den Tod der Versuchsmäuse Pr. 111 und 112 herbeiführt. Wesentlich andere Eigenschaften zeigt nun das 15 Minuten auf $60^{\circ}$ erwärmte und in gleichen Mengen wie das native Serum verwendete Immunserum bei Pr. 114 und 114a. Zunächst tritt eine verstärkte Trypanozidie des erwärmten Serums in die Erscheinung. Erst 24 Stunden nach dem Tode der Infektionskontrollen sind die mit dem auf $60^{\circ}$ erhitzten Serum in vitro digerierten Trypanosomen bei Pr. 114 und 114a in der Zirkulation nachweisbar, und am 3. Versuchstage sind die Versuchstiere noch trypanosomenfrei, zu einer Zeit, wo die Infektion der mit natirem, unerhitztem Immunserum im Reagenzglase behandelten Ausgangsstammparasiten bei Pr. 111 und Pr. 112 voll entwickelt erscheint. Mit dieser deutlicheren Ausprägung der Trypanozidie des auf $60^{\circ}$ erhitzten Immunserums geht Hand in Hand ein unter dem Einfluß der Erwärmung sich vollziehender Schwund der rezidivstammbildenden Eigenschaften des Immunserums. Denn im Gegensatze zu Pr. 111 und Pr. 112 geht bei Pr. 114 und 114a die Nachinfektion mit dem Ausgangsstamm nicht an. Es vermag somit die 15 Minuten lange Erhitzung des Immumserums auf $60^{\circ}$ dessen trypanozide Fähigkeiten zu steigern ${ }^{1}$ und gleichzeitig seine rezidivstammbildenden Funktionen zu zerstören.

Durch diesen Befund der verschiedenen Thermoresistenz der trypanoziden und rezidivstammbildenden Substrate der Trypanosomenimmunsera erhält unsere Annahme von der Wesens-

1 Anmerkung: Wir begegnen hier vielleicht ähnlichen Verhältnissen, wie sie Morgenroth und Rosenthal für die auf $65^{\circ}$ erwärmten hämolytischen ImmunAmbozeptoren beschrieben haben, deren veränderte globalizide Eigenschaften n. a. in einer Beschleunigung der Hämolyse zum Ausdruck gelangen. 
Genese des Rezidivs B. D. experim. Trypanosomeninfektion.

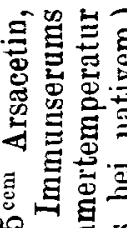

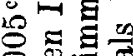

过

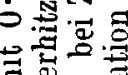

这

$80 \circ 8$ है

$\cong$ in 0 응

음

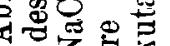

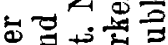

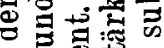

등 해원

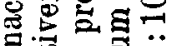

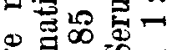
to

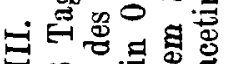

离总

㝵

-

$\because+0$,

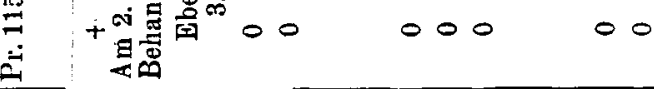

政 00

(2) की

二

윽그응

- 0

๘

政品

.

乙需

$=\%$

짐.

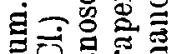

记

等

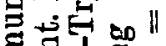

छ

몽흘

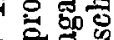

电㧧

$.00+$

:

$\infty$ 慁 +

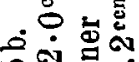

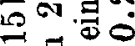

ㄱ.

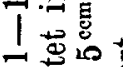

北宗家

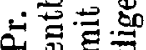

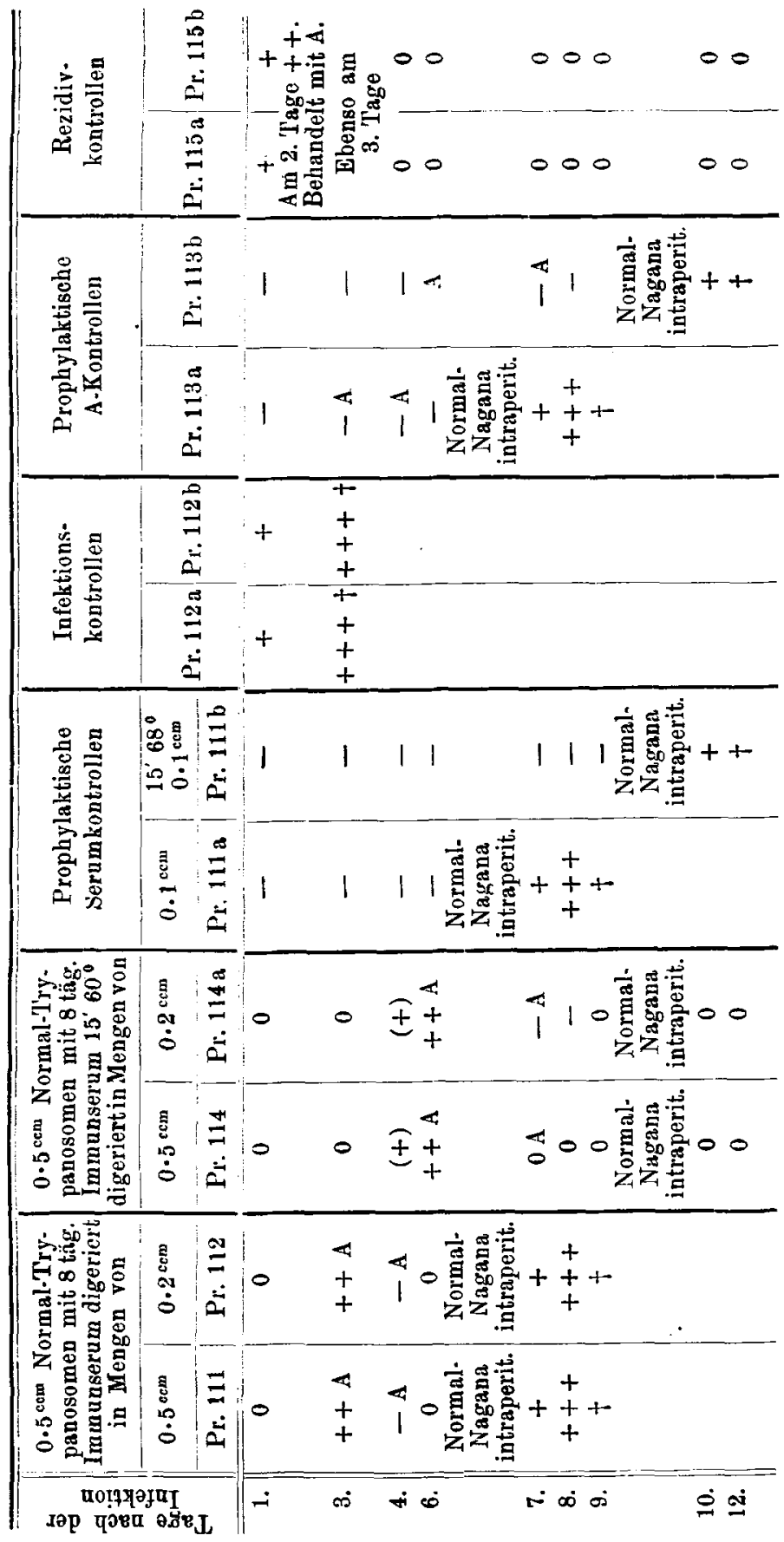


differenz der trypanoziden Immunkörper und der Rezidirlörper ihre weitere experimentelle Stätze. Besonders bemerkenswert erscheint uns die Beobachtung, daB mit der elektiven thermischen Vernichtung der Rezidivkörper die trypanozide Kraft des Immunserums ansteigt. Es weist dies darauf hin, daB zwischen den trypanoziden Immunsubstanzen und den Rezidivkörpern vielleicht ein Antagonismus besteht in dem Sinne, daB, je reicher der Gehalt der Immunsera an Rezidivkörpern ist, um so weniger die trypanoziden Substanzen auf die Trypanosomenzelle zur Wirkung gelangen.

Versuche, durch Spaltung des Immunserums in seine Globulin- und Albuminfraktion die trypanoziden und Rezidivkörper zu analysieren, fübrten zu weiteren positiven Ergebnissen bezüglich der Sonderexistenz der beiden Serumsubstrate und ergaben insbesondere als Resultat, daB die rezidivstammbildende Komponente trypanozider Immunsera wohl zum wesentlichen Teile an die Albuminfraktion des Serums gebunden ist. Unsere Versuchsmethodik knüpfte an das von Liefmann zur Spaltung des Komplementes angegebene Verfahren an, nach welchem die Ausfällung der Globuline durch Einleiten ron Kohlensäure geschieht, ein Verfahren, das auch nach den Erfahrungen von Braun als ein recht schonendes betrachtet werden kann. Im einzelnen gestaltete sich unser Verfahren folgendermaBen:

Von ihrer Trypanosomeninfektion geheilte Mäuse werden 4-5 Tage nach der chemotherapeutischen Behandlung in physiologische Kochsalzlösung $(0.15 \mathrm{~cm}$ pro Maus) entblutet. Ein Teil der so gewonnenen Mäuseblutaufschwemmung wird nun im Becherglase mit der zehnfachen Menge destillierten Wassers gemischt und danach Kohlensäure aus einer Bombe eingeleitet. Es tritt alsbald eine in kurzer Zeit ihr Maximum erreichende flockige Trübung der Flüssigkeit auf, und durch sofort sich ansehlieBendes Zentrifugieren erzielt man eine Abtrennung des Globulinniederschlages von der klaren, durchsichtigen Flüssigkeit, welche die Albuminfraktion enthält. Die albuminhaltige Flüssigkeit wird nun durch Abgießen von dem Globulinsediment getrennt, worauf beide Serumfraktionen zwecks Reinigung einer gesonderten Behandlung unterworfen werden. Die Flüssigkeit wird nochmals um der Vollständigkeit der Ausfällung sicher zu sein, mit Kohlensäure behandelt, dann durch ein doppelt gehärtetes Papierfilter filtriert und durch Zusatz von Kochsalzkörnehen in entsprechender Menge auf den physiologischen Salzgehalt gebracht, um schlieBlich zwecks Entfernung der Kohlensäure in einem weiten offenen Gefäße öfters kräftig geschüttelt zu werden.

Der Globulinniederschlag wurde zweimal mit Aq. dest. gewaschen und hierauf entsprechend der ursprünglichen zehnfachen Serumverdünnung in so viel Kubikzentimeter $\mathbf{0 . 8 5}$ Prozent Kochsalzlösung gelöst, daßs Albuminund Globulinlösung gleiche Flüssigkeitsvolumina repräsentierten. Weitere Einzelheiten der Methodik sind aus den folgenden Protokollen ersichtlich. 


\section{Versuch XIV.}

Pr. 135-141. 4tägiges Immunserum. (3 Nagana-Mäuse, 4 Tage nach der Abbeilung mit $2 \mathrm{mal} 0.005$ Arsacetin subkutan, entblutet in $0.45 \mathrm{ccm}$ 0.85 prozent. $\mathrm{NaCl}-L o ̈ s u n g ; ~ 1.1 \mathrm{~cm}$ Flüssigkeit). Hiervon:

A. Pr. 135: $0 \cdot 2^{\mathrm{cm}}$ natives Immunserum $+1.8 \mathrm{~cm} 0.85$ prozent. $\mathrm{NaCl}$ Lösung (Verdünnung 1:10), davon $0.4{ }^{\mathrm{cem}}$ Immunserum $+04{ }^{\mathrm{ecm}} 0.85$ prozent. $\mathrm{NaCl}$-Lösung $+0.5^{\mathrm{cm}}(+++)$-Normal-Naganaaufschwemmung in physiologiseher Kochsalzlösung.

B. Pr. 137 und Pr. 139: $0.9 \mathrm{~cm}$ natives Immunserum $+8.1 \mathrm{~cm}$ Aq. dest. Behandlung mit $\mathrm{CO}_{2}$, Gewinnung der Globulin- und Albuminfraktion.

Pr. 137: Globulinniederschlag in 9 em 0.85 prozent. NaCl-Lösung gelöst. (Verdïnnung $1: 10$ ), davon $0.4 \mathrm{~cm}$ Globulinlösung $+0,4^{\mathrm{cm}} 0.85$ prozent.NaCl-Lösung $+0.5^{\mathrm{cm}}(+++)$-Normal-Naganaaufschwemmung in physiologischer Kochsalzlösung.

Pr. 139: Albuminlösung, isotonisch gemacht. (Verdünnung 1:10, davon $0.4^{\mathrm{cem}}$ Albuminlösung $+0.4^{\mathrm{cem}} \mathbf{0 . 8 5}$ prozent. $\mathrm{NaCl}-\mathrm{Lösung}+0.5^{\mathrm{cm}}$ $(+++)$-Normal-Naganaaufschwemmung in physiologischer Kochsalzlösung.

C. Pr. 141: 0,4 $\mathrm{cm}$ Albuminlösung (Verdünnung $1: 10)+0.4^{\mathrm{cm}}$ Globulinlösung $(1: 10)+0,5^{\mathrm{cen}}(+++)$-Normal-Naganaanfschwemmung in physiologischer Kochsalzlösung.

$0.2^{\mathrm{ccm}}$ der Mischungen nach 10 Minuten langer Digerierung bei Zimmertemperatur weißen Mäusen intraperitoneal. $\mathbf{A}=$ Behandlung mit Arsacetin, $0.5^{\mathrm{cm}} 1: 100$ subkutan.

\section{Versuch XV.}

Pr. 143-150. 5 tägiges Immumserum. (2 Nagana-Mäuse, 5 Tage nach der Abheilung mit $2 \mathrm{mal} 0.005$ Arsacetin subkutan, entblutet in $0.3^{\mathrm{ccm}}$ 0.85 prozent. NaCl-Lösung, $1 \cdot 0^{\mathrm{cm}}$ Flüssigkeit). Hiervon:

A. Pr. 143 und Pr. 144: $0.1^{\mathrm{cm}}$ natives Immunserum $+0.9^{\mathrm{cmm}} 0.85$ prozent. NaCl-Lösung (Verdünnung 1:10), davon $0.4^{\mathrm{ccm}}$ bzw. $0.2^{\mathrm{ccm}}$ Immunserum $+0.4^{\mathrm{ccm}}$, bzw. $0.6^{\mathrm{cm}} 0.85$ prozent. NaCl-Lösung $+0.5^{\mathrm{cm}}(+++)$ Normal-Naganaaufschwemmung in physiologiseher Kochsalzlösung.

B. Pr. 145 und Pr. 146, Pr. 147 und Pr. 148: $0.9^{\mathrm{cm}}$ natives Immunserum $+8 \cdot 1 \mathrm{~cm}$ Aq. dest. Behandlung mit $\mathrm{CO}_{2}$, Gewinnung der Globulinund Albuminfraktion.

Pr. 145 und Pr. 146: Globulinniederschlag in $9^{\mathrm{cem}} 0.85$ prozent. $\mathrm{NaCl}-$ Lösung gelöst (Verdünnung $1: 10$ ), davon $0.4^{\mathrm{cm}}$, bzw. $0.2^{\mathrm{cem}}$ Globulinlösung $+0.4^{\mathrm{cem}}$, bzw. $0.6^{\mathrm{cem}} 0.85$ prozent. NaCl-Lösung $+0.5^{\mathrm{ccm}}(+++)$ Normal-Naganaaufschwemmung in physiologischer Kochsalzlösung.

P. 147 und Pr. 148: Albuminlösung, isotonisch gemacht (Verdünnung $1: 10$ ), davon $0.4^{\mathrm{ccm}}$, bzw. $0 \cdot 2^{\mathrm{ccm}}$ Albuminlösung $+0 \cdot 4^{\mathrm{ccm}}$, bzw. $0.6^{\mathrm{ccm}}$ 0.85 prozent. NaCl-Lösung $+\mathbf{0 . 5} \mathrm{scm}^{\mathrm{cm}}(++)$-Normal-Naganaaufschwemmung in physiologischer Kochsalzlösung.

C. Pr. 149 und Pr. 150:0,4 $\mathrm{cm}$ Globulinlösung (Verdünnung $1: 10$ ) $+0.4^{\mathrm{cem}}$ Albuminlösung (Verdünnung $\left.1: 10\right)+0.5^{\mathrm{ccm}}(+++)$-NormalNaganaaufschwemmung in physiologischer Kochsalzlösung, bzw. $0 \cdot 2^{\mathrm{ccm}}$ Glo- 


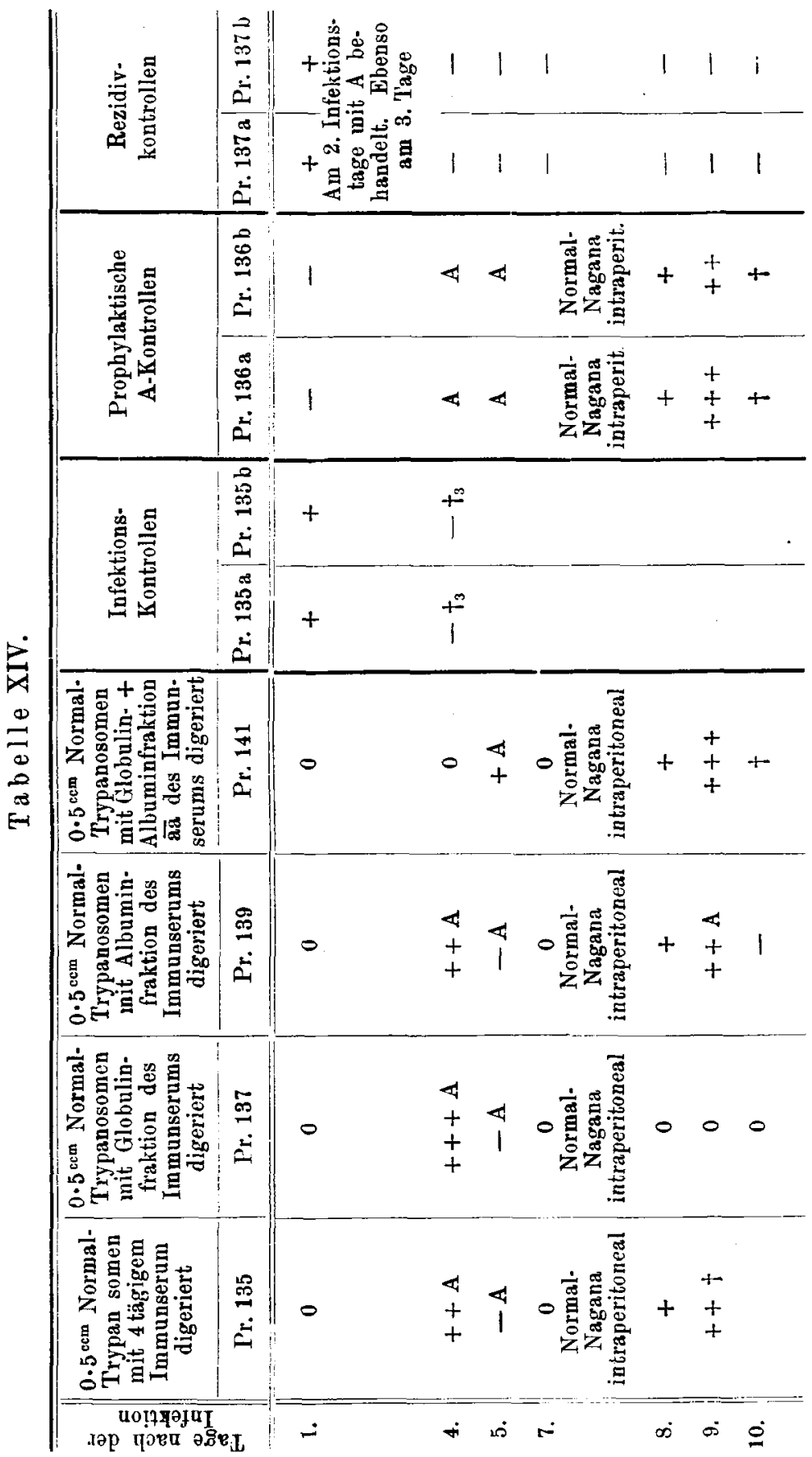




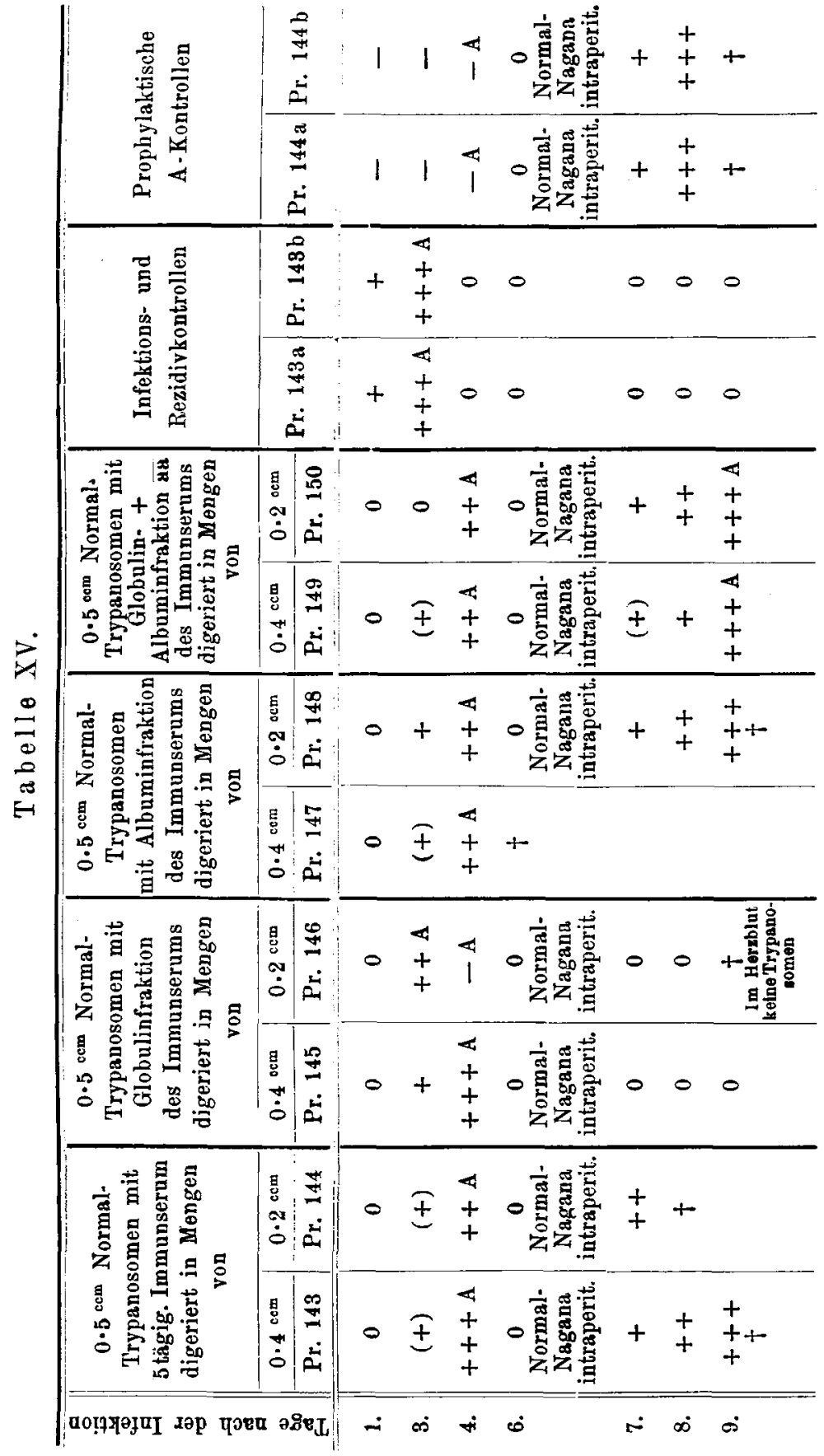


bulin- $+0,2^{\mathrm{ccm}}$ Albuminlösung $(1: 10)+0 \cdot 4^{\mathrm{ccm}} 0 \cdot 85$ prozent. NaCl-Lösung $+0.5^{\mathrm{cem}}$ Normal-Naganaaufschwemmung in physiologischer Kochsalzlösung.

$0.2^{\mathrm{cm}}$ der Mischung nach 10 Minuten langer Digerierung bei Zimmertemperatur weißen Mäusen intraperitoneal. $\mathrm{A}=$ Behandlung mit Arsacetin $0 \cdot 5^{\mathrm{cm}} 1: 100$ subkutan.

Das Resultat beider Versuche ist übereinstimmend. Sowohl in Tabelle XIV wie XV kommen nur der Albuminfraktion bei Pr. 139 und P. 148 rezidivstammbildende Eigenschaften zu, während der Kontakt der Normal-Trypanosomen mit der Globulinfraktion des Immunserums in Pr. 145 und Pr. 146 nicht ausreicht, um sie zu Trägern von Rezidivstammeigenschaften umzuprägen. Daher bleibt bei Pr. 137, 145 und 146 die Nachinfektion mit dem Ausgangsstamm im Gegensatz zu Pr. 139 und 148 auch erfolglos. Bemerkenswert erscheint weiter bei diesen Versuchen, daB die trypanoziden Funtionen der Trypanosomenimmunsera sich sowohl in der Globulin-wie in der Albuminfraktion der Sera finden, wie die gleichmäßig verzögerte Infektion bei Pr. 135, $137,139,141,143-150$ anzeigt, während die rezidivstammbildenden Eigenschaften der Immunsera wohl größeren, vielleicht gröBtenteils in die Albuminfraktion abergehen. Es weisen auch diese Befunde darauf hin, daB die trypanoziden Antikörper und die rezidirbildenden Komponenten spezifischer Trypanosomenimmunsera gesondert existieren und nicht Manifestationen eines einzigen Serum. körpers darstellen.

Wir möchten nun im folgenden über Versuche berichten, welche sich mit der Frage der Vererbbarkeit der erworbenen Rezidivstammeigenschaften beschäftigen.

Wir haben bereits oben hervorgehoben, daB die in der Literatur hierüber niedergelegten Erfahrungen nicht übereinstimmen, daB Ehrlich eine jahrelange Vererbung der Rezidivstammeigensehaften bei seinen Stämmen beobachtet hat, daB dagegen Mesnil und Brimont, Neumann, Braun und Teichmann einen Rückschlag der Rezidivparasiten zu NormalTrypanosomen im Verlaufe der Passagen feststellen konnten. Wir hatten nun Gelegenheit, bei einem unserer in vitro durch Serumkontakt erzeugten Rezidivstämme, dessen Genese wir im Versuch VII wiedergegeben haben, die Rückverwandlung des Rezidivstammes in den Ausgangsstamm in ihren verschiedenen Stadien zu verfolgen. Die hierbei gewonnenen Ergebnisse dürften vielleicht ein Verständnis für die differenten Beobachtungen der genannten Autoren eröffnen. 
Während nämlich Braun und Teichmann auf Grund ihrer Versuche, die schlieBlich zur Feststellung der völligen Rückverwandlung des Rezidirstammes in den Ausgangsstamm führten, zu der Überzeugung gelangen, daB der Rezidivstamm bei der experimentellen Trypanosomeninfektion nicht als eine Mutation, sondern als eine vorübergehende Anpassung an aufoktroyierte Schädlichkeiten anzusehen sei, weisen unsere eigenen Experimente darauf hin, daB der Rezidivstamm sich aus Individuen vom Typus der echten Mutation und Individuen der einfachen nichterblichen Variation zusammensetzen kann, und daß der Rückschlag des Rezidivstammes in den Normalstamm keinen Rückschlag aller Parasiten in toto darzustellen braucht, sondern auf einem Uberwuchern von zum Normalstamm zurückschlagenden Varianten über die an Zahl zurücktretenden Mutanten beruhen kann.

Die Prüfung des frisch gewonnenen Rezidirstammes ergab, wie Tabelle VII demonstriert, daB die an seine Abheilung sich anschlieBende Immunität des Wirtstieres nicht gegen den Ausgangsstamm gerichtet war. Ebenso zeigte sich in der 5. Passage dieses Rezidivstammes durch unbehandelte Mäuse, dab die Abheilung von mit Normal-Nagana infizierten Mäusen keinen Schutz gegen eine Nachinfektion mit dem Rezidivstamm bewirkte (M. 151-153).

Versuch XVI. (S. 527.)

Vorinfektion mit Normal-Nagana. Abheilung mit Arsacetin 0.5 ecur 1: 100 subkutan (A). Nachinfektion mit Rezidirstamm in vitro (vgl. Tabelle VII) 5. Passage.

Wir züchteten unseren Rezidivstamm zunächst in normalen Mäusen weiter und prüften dann in der 24. Passage von neuem sein biologisches Verhalten. Dabei ergab sich, wie dies aus den Tabellen XVII und XVIII (S. 528) ersichtlich ist, daB der Rezidivstamm sich inzwischen in wesentlichen Eigenschaften verändert hatte und zur Zeit des Experimentes weder mit dem frisch gewonnenen Rezidirstamm noch mit dem normalen Ausgangsstamm identisch war.

\section{Versuch XVII.}

Vorinfektion mit Nagana normal. Heilung mit Arsacetin $0,5^{\mathrm{ccm}} 1: 100 \mathrm{sub}-$ kutan A. Nachinfektion mit Nagana normal und Rezidivstamm in vitro (24. Passage).

Während in Tabelle XVI (vgl. M. 151/53) die Heilung einer Infektion mit Normal-Naganastamm keine Immunität gegen eine Nachinfektion mit dem Rezidivstamm hinterlieB, erleidet in der 24. Passage bei Maus 204 bis 206 (Tabelle XVII) durch den an die Abheilung des Normalstammes sich 
anschließenden Immunitātszustand die Infektion mit dem Rezidivstamm eine deutliche Verzögerung. Während die Infektionskontrollen (M. 209/10) des Rezidivstammes 24 Stunden nach der Infektion bereits die Trypanosomenseptikämie auf der Höhe ihrer Entwicklung zeigen, finden sich bei der in gleicher Weise vorgenommenen Reinfektion der Mäuse 204-206, die eben eine Infektion mit Normal-Nagana überstanden haben, nach dem gleichen Zeitraum erst vereinzelte Parasiten in der Zirkulation. Noch markanter ergibt sich die Veränderung des durch 24 normale Măusepassagen geschickten Rezidivstammes aus Tabelle XVIII (vgl. S. 528).

\section{Versuch XVIII.}

Vorinfektion mit Rezidivstamm in vitro (24. Passage). Heilung mit Arsacetin $0.5^{\mathrm{ecm}}$ 1:100 subkutan (A). Nachinfektion mit Nagana normal und Rezidivstamm in vitro (24. Passage).

Hier vermag im Gegensatz zu dem entsprechenden Versuch der Tabelle VII (vgl. Pr. 17-20) die Vorinfektion und Abheilung des Rezidivstammes das Angehen der Nachinfektion mit dem Ausgangsstamm definitiv zu verhindern (M. 211-213, Tabelle XVIII).

Es hat somit im Verlaufe der normalen Tierpassagen dieser Rezidirstamm noch die Eigenschaften des Ausgangsstammes zurückgewonnen, er ist nunmehr in seinem biologischen Verhalten Rezidirstamm und Normalstamm zugleich.

Soweit stimmen unsere Ergebnisse mit einer analogen Beobachtung Brauns und Teichmanns überein. Während jedoch Braun und Teich mann aus ihren Versuchen den SchluB ziehen, daB der Rezidivstamm gewissermaBen einen Zwangszustand der Trypanosomenzelle darstelle, in den sie durch aufoktroyierte Schädlichkeiten gewaltsam hineingedrängt werde, und aus dem in den Ausgangstamm zurückzukehren, ihre physiologische Tendenz sei, haben wir in den folgenden Experimenten, die für das Verständnis des Rückschlages des Rezidirstammes zum Ausgangsstamme wesentliche Frage zu entscheiden versucht, ob an der Rückbildung alle Trypanosomenindividuen gleichmäBig teilnehmen oder ob der ProzeB des Rücrschlages nur gewisse Individuen betrifft, die schlieBlich zu überwuchern vermögen. Aus dem verzögerten Angehen des Rezidivstammes bei M. 204-206 (Tabelle XVII) folgerten wir nämlich, daB mit Wahrscheinlichkeit der Rezidirstamm zurzeit zahlreiche Normalindividuen wieder enthalte, welche die nur spärlich angehenden Parasiten rom Typus des Rezidivstammes zu überwuchern im Begriffe waren. Mit der Anwesenheit dieser Normalparasiten war das Ausbleiben der Nachinfeltion mit dem Ausgangsstamm in den Mäusen M. 211-213 hinreichend erklärt (Tabelle XVII). 


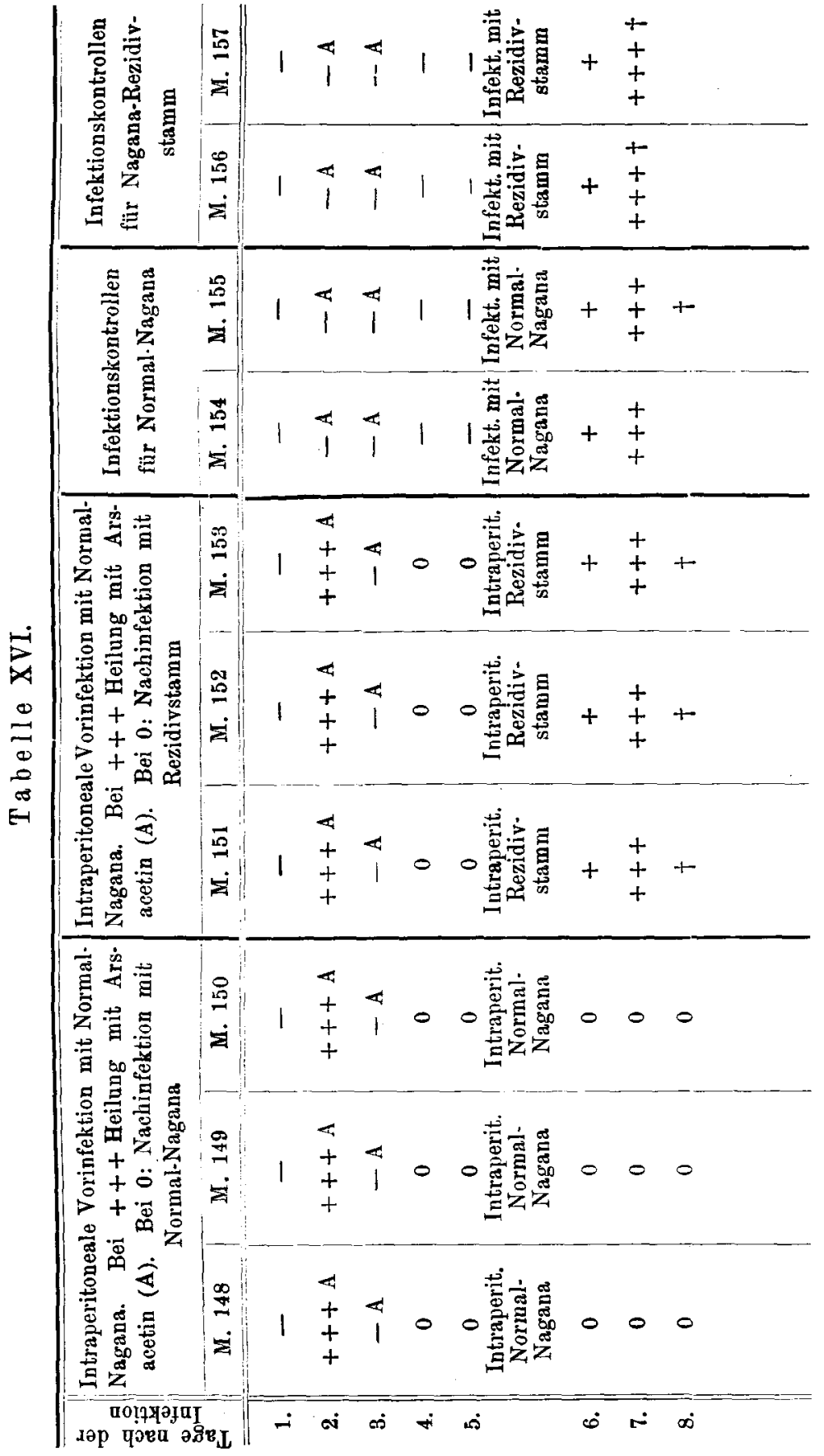




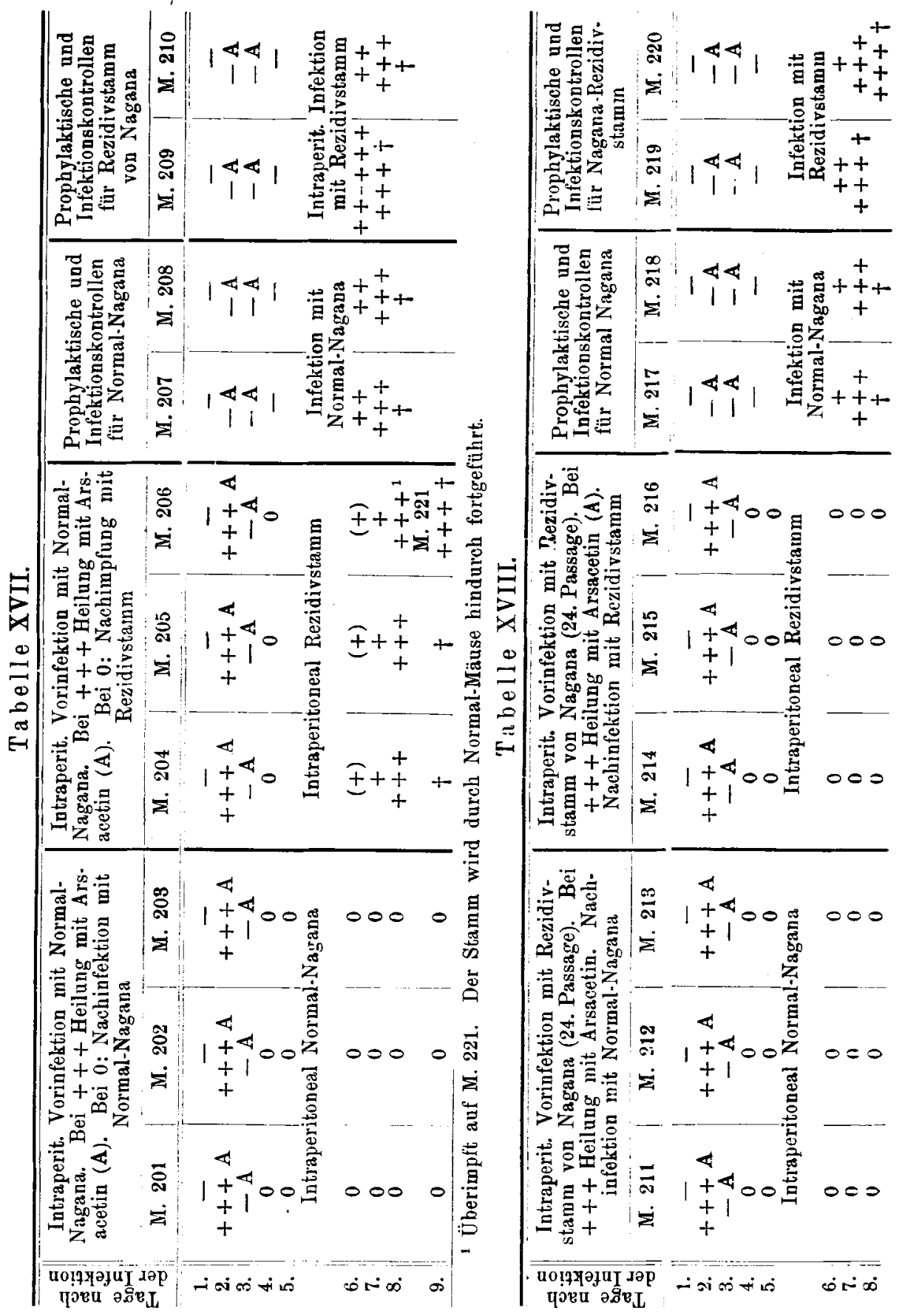


Wenn diese Deutung der Versuchsergebnisse der Tabelle XVII und XVIII den Tatsachen entsprach, wenn mit anderen Worten der allmählich sich vollziehende Rückschlag des Rezidirstammes zum Normalstamm auf einem Überwuchern der zur Norm zurückkehrenden Variantentypen über die Mutantentypen beruhte, so war zu erwarten, daB mit der Nachinfektion des Rezidivstammes in die mit Normalstamm infizierten und abgeheilten Mäuse M. 204-206 der Rezidirstamm eine Siebung, einen Filtrationsprozeb erfahren und so von seinem Gehalt an NormalTrypanosomen gereinigt werden würde, indem diese der abtötenden Wirkung der gegen den Normalstamm gerichteten Antikörper unterliegen. Nach dieser Vorstellung muBten die unter diesen Bedingungen noch angehenden Trypanosomen die typischen Rezidivstammeigenschaften rein zeigen und lange Zeit rein vererben, da, sofern im Sinne der Ehrlichschen Auffassung die Genese des Rezidirstammes auf Prozesse der echten Mutation zurückgeht, unter diesen "gesiebten" Trypanosomen die echten, ihre neu erworbenen Eigenschaften vererbenden Individuen zu finden sein mußten.

Diese Voraussetzung traf auch in der Tat $z u$, indem wir zeigen konnten, daB der "gesiebte" ron Maus 206 auf Ll. 221 überimpfte und durch Normalmãuse weitergeführte Stamm nach weiteren 24 Passagen unverändert seine Rezidivstammeigenschaften gewahrt hatte, während der ,unfiltrierte" Rezidirstamm nach der gleichen Zahl ron Passagen (in der 50. Passage nach Gewinnung des Rezidirstammes) wieder rollkommen die Eigenschaften des Ausgangsstammes angenommen hatte.

Tabelle XIX u. XX (S. 530 u. 531) veranschaulichen dieses differente Verhalten des „ungesiebten" Rezidivstammes, der also in der üblichen Weise von Normalmaus auf Normalmaus übertragen worden war, und des „gesiebten" Rezidirstammes, der ein einziges Mal in M. 206 (Tabelle XVII) durch eine mit Normal-Nagana infizierte und abgeheilte Maus hindurchgeschickt und dann weiter in den unbehandelten Mäusen fortgezüchtet wurde. Der ,ungesiebte" Rezidivstamm verhält sich hiernach in M. 322-24 (Tabelle XIX) und M. 331-333 (Tabelle XX) völlig wie der Ausgangsstamm, indem sowohl die bei der Abheilung des Ausgangsstammes entstehenden spezifischen Antikörper eine erfolgreiche Nachinfektion mit dem ursprünglichen Rezidivstamm verbindern, als auch die bei der Abheilung des ursprünglichen Rezidirstammes auftretenden Immunstoffe auf Trypanosomen des Ausgangsstammes trypanozid wirken. DaB es sich hierbei um ein Ubberwuchern von nur passager festen, relativ leicht zur Norm zurückkehrenden Parasiten rom Variationstypus handelt, zeigt dann M. 325-327 (Tabelle XIX) und M. 334-336 (Tabelle XX), in denen der "gesiebte", offenbar nur noch Mutanten enthaltende Stamm, sowohl bei 


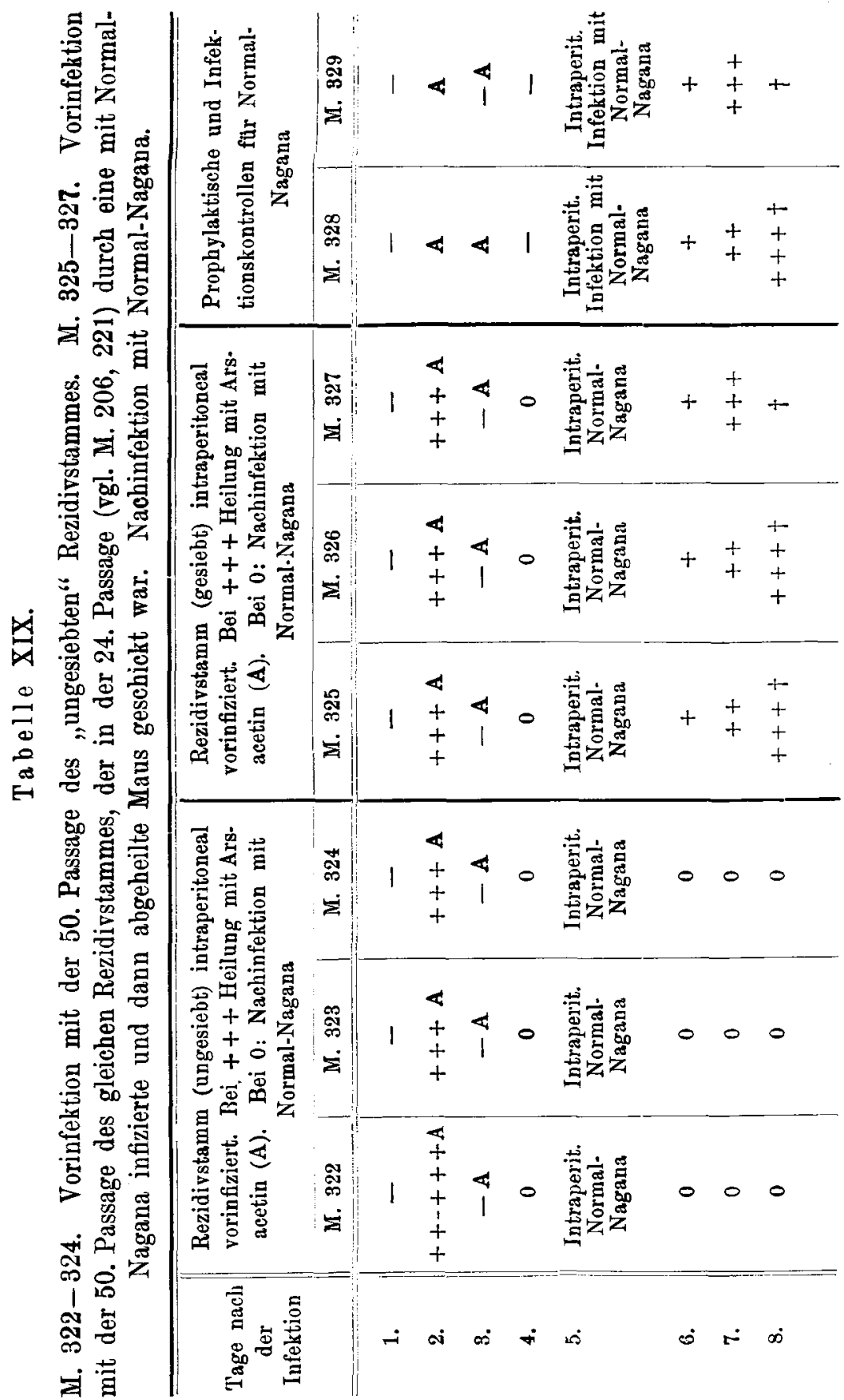


Genese des Rezidivs B. D. experim. Trypanosomeninfektion. 531

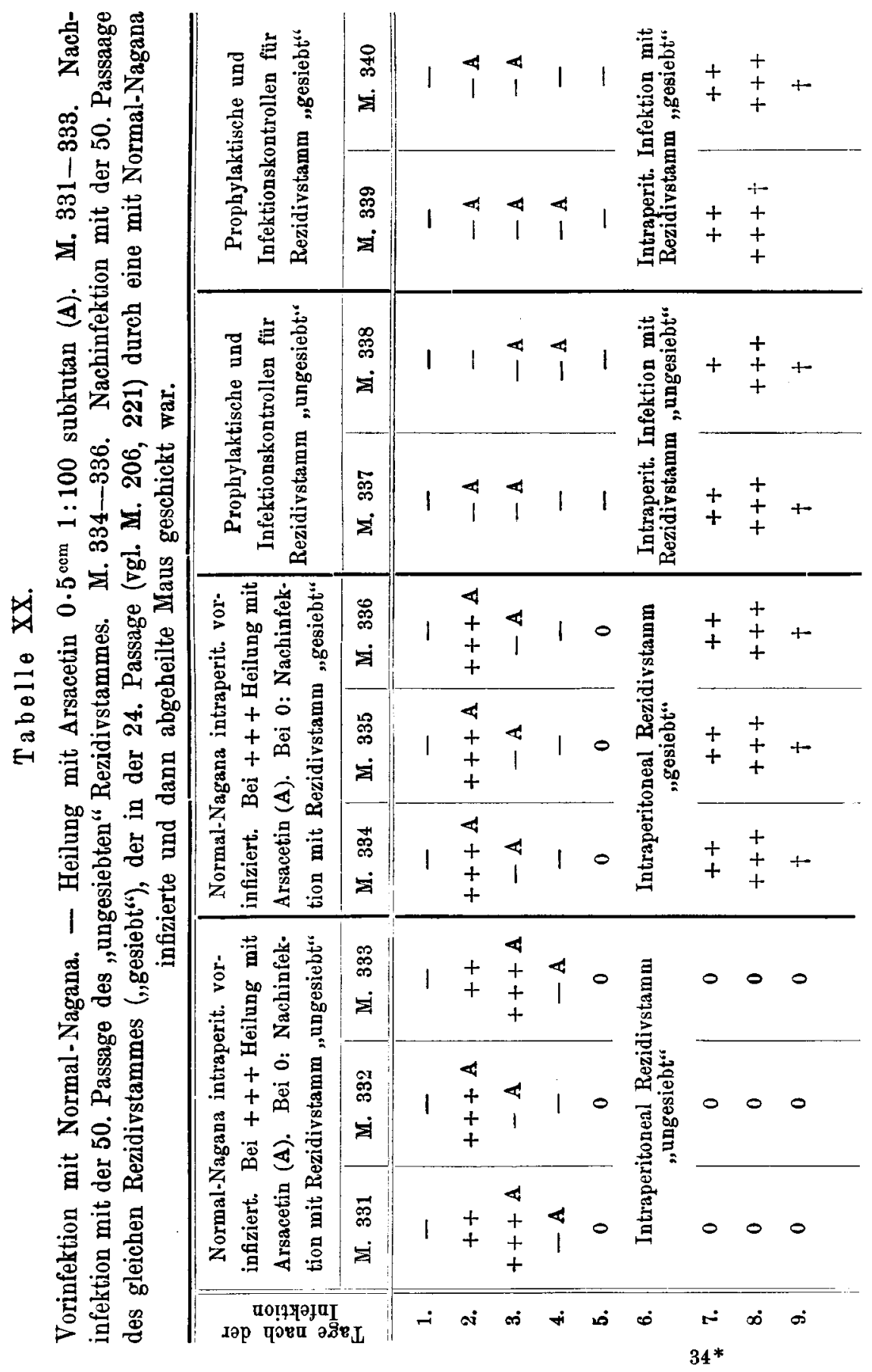


Vorinfektion wie Nachinfektion hinsichtlich der Immunitätsreaktion alle charakteristischen Eigenschaften des Rezidirstammes rein trotz gleicher Passagenzahl aufweist.

Wir können somit 7usammenfassend sagen:

Der Rezidirstamm stellt je nach der Intensitāt der Immunitätsvorgänge und je nach der Individualität der Trypanosomen des Ausgangsstammes entweder im Sinne der Ehrlichschen Anschaung eine echte Mutation dar, die ihre neuen Eigenschaften durch die Generationen ungemindert forterbt, oder eine Mischung (Population) von Mutanten- und Variantentypen, ron denen letztere früher oder später zur Norm zurüchschlagen. Ob der Rezidirstamm auch ausschlieBlich als reine Variation bestehen kann und sich nur aus vorübergehend angepaBten Variationsformen des Ausgangsstammes gemäB Braun-Teichmann zusammensetzen kann, muB vorläufig dahingestellt bleiben. Unsere Versuche zeigen, daß der Rückschlag des Rezidivstammes zum Ausgangsstamm durchaus nicht auf einem Rückschlag aller Parasiten zu beruhen braucht, sondern sich auch bei Anwesenheit echter Mutationsformen durch Überwuchern. der Variationstypen rollziehen kann.

-Wir sind schlieblich in weiteren Experimenten der Frage näher getreten, wie sich die in vitro erzeugten Rezidirstämme zu den spontan im Verlaufe der Infertion auftretenden Rezidirstämmen verhalten, und ob auch zwischen den in gleicher Weise durch Serumkontakt im Reagenzglase entstandenen Rezidirstämmen untereinander biologische Unterschiede bestehen, die sich in dem Ausfall der Immunitätsreaktion offenbaren. Für die spontan im Verlaufe der Trypanosomeninfertion auftretenden Rezidirstämme hat zuerst Neumann im Morgenrothschen Laboratorium gezeigt, daB die Immunität, welche sich an die Abheilung des einen Rezidivstammes anschlieBt, noch nicht notwendigerweise eine Immunität gegen. andere Rezidirstämme desselben Ausgangsstammes bedingen muB, ja, daB selbst auch auf völlig gleiche Art und Weise mit demselben Heilmittel erzeugte und in derselben Periode stehende Rezidirstämme des gleichen Ausgangsstammes bei der Immunitätsreaktion biologische Unterschiede zeigen können. Ehrlich hat dann diese Befunde dahin erweitert, daB mit Wahrscheinlichkeit nur fünf derartige unter sich differente Modifikationen von Rezidirstämmen bestehen. Auch Braun und Teichmann sind in ibren Versuchen zur Immunisierung gegen Trypanosomen zu dem Ergebnis gelangt, daB unter der Einwirkung derselben Antikörper rerschiedene Arten ron serumfesten Stämmen entstehen können. 
In zwei verschiedenen Versuchskombinationen wurde eine Beantwortung der eingangs von uns aufgeworfenen Frage versucht:

1. Durch Vergleichung eines im Reagenzglase durch Immunserumkoutakt gewonnenen Rezidivstammes mit einem spontan sich entwickelnden I. Rezidivstamm.

2. Durch Gegenüberstellung ron Rezidirtrypanosomen, die auf völlig gleiche Weise nur mit verschiedentägigem Immunserum im Reagenzglase durch Serumkontakt aus Normal-Trypanosomen gewonnen waren.

ad 1. Von Pr. 144 (Tabelle XV) werden am 4. Versuchstage die reichlich entwickelten Trypanosomen auf eine unbehandelte Maus subkutan übertragen (sehr schwache Infektion). Sobald durch die erfolgreiche Nachinfektion mit Normal-Nagana die Umwandlung des mit Immunserum in vitro behandelten Ausgangsstammes zum Rezidivstamm bei Pr. 144 gesichert ist, wird die mit diesen Rezidivparasiten frisch infizierte Maus entblutet, und die Mäuse I-IX, XV stark intraperitoneal mit dem Blut infiziert. Bei +++ im Blut werden diese Tiere mit Arsacetin geheilt, und nun NormalNagana (I-III), gleicher Rezidivstamm in vitro (IV-VI) und ein I. Tartarusrezidivstamm nachgeimpft. Über die Gewinnung dises Rezidivstammes ist kurz zu sagen, dab er von den Trypanosomen eines ersten Rezidives gewonnen war, das nach Abheilung der Normal-Naganainfektion durch $0 \cdot 25 \mathrm{~cm}$ einer Lösung von Kaliumantimonyltartrat 1:1000 subkutan am 10. Tage auftrat. Er wurde nach einer Tierpassage zum Versuche verwendet.

\section{Versuch XXI. (S. 534.)}

Das Resultat des Versuches ist also folgendes: Die Abheilung des Rezidivstammes in vitro bewirkt nur eine Immunität gegen diesen Stamm, nicht aber gegen den Ausgangsstamm, und vor allem nicht gegen einen spontan entstandenen entsprechenden I. Rezidivstamm. Es zeigen somit beide Rezidivstämme neben ihrer gemeinsamen Eigenschaft, rom Ausgangsstamm verschieden zu sein, noch untereinander differente biologische Merkmale: die gegen den einen Rezidirstamm gerichteten spezifischen Schutzstoffe besitzen keine Wirksamkeit für den anderen Rezidirstamm.

Entsprechenden Verhältnissen begegnen wir, wenn wir zwei durch Kontakt mit verschiedentägigem Immunserum gewonnene Rezidivstämme mit Hilfe der Immunitätsreaktion miteinander vergleichen. Es wurden im folgenden Versuch XXII 4 Mäuse mit der 3. Passage des Rezidivstammes Pr. 135 (Tabelle XIV), der durch Behandlung von Normaltrypanosomen in vitro mit 4 tägigem Immunserum gewonnen war, intraperitoneal infiziert, mit Arsacetin abgeheilt, und Trypanosomen des Rezidirstammes Pr. 144 (Tabelle XV) nachinjiziert, der sich aus Normalparasiten durch Digerierung mit 5 tägigem Immunserum im Reagenzglase entwickelt hatte und in diesem Versuch in der 2. Passage zur Verwendung gelangte. 


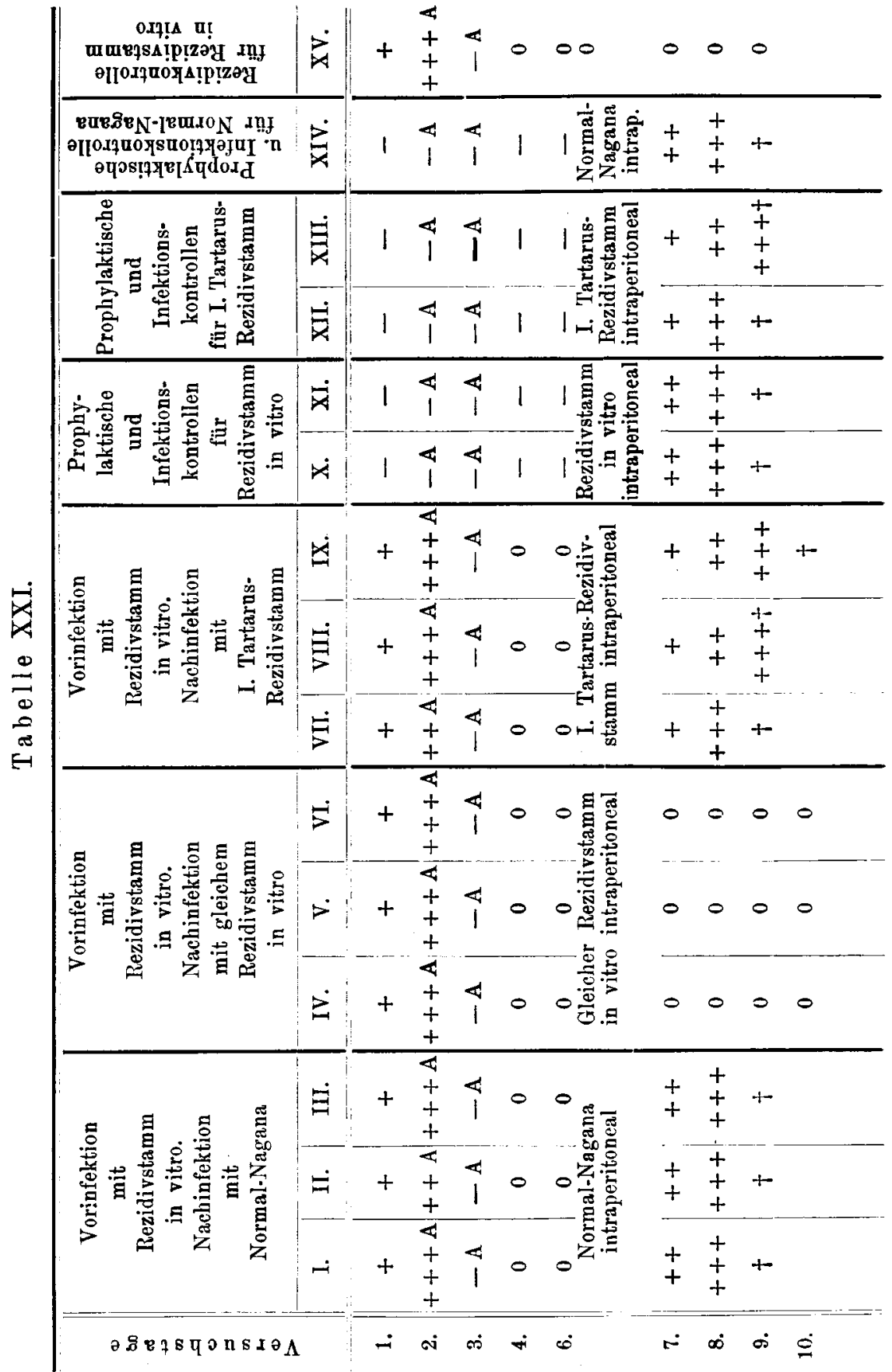


Genese DES Rezidivs B. D. EXPERIM. TRYPANosomentNFEKTION. 535

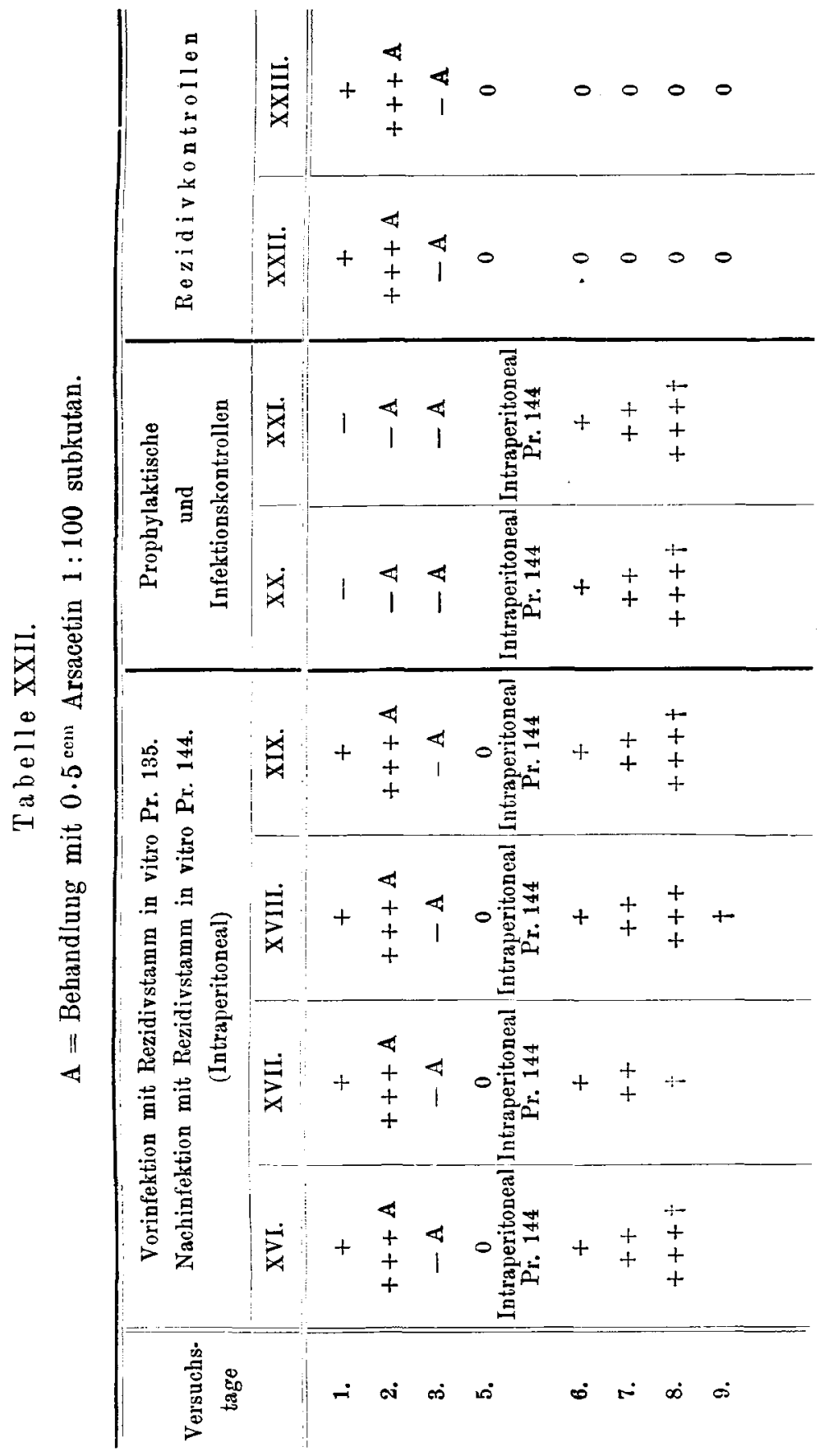


Das Ergebnis dieses Experiments ist: Auch auf gleiche Art mit verschiedentägigem Immunserum im Reagenzglasversuch erzeugte Rezidivtrypauosomen zeigen bei Anwendung der Immunitätsreaktion biologische Unterschiede. Denn, wie der Versuch zeigt, vermag die Vorimpfung und Abheilung des Rezidirstammes in vitro Pr. 135 keine Schutzkörper gegen die nachfolgende Infektion mit dem Rezidivstamm in vitro Pr. 144 auszulösen. Wir begegnen somit auch bei den im Reagenzglașversuch gewonnenen Rezidirstämmen analogen Verhältnissen, wie sie ron Neumann, Ehrlich, Braun und Teichmann bei den spontan auftretenden Rezidivstämmen beschrieben worden sind.

\section{Zusammenfassung.}

I. Die im rorangehenden geschilderten Versuche beschäftigen sich mit dem Mechanismus der Rezidivstammbildung bei der experimentellen Trypanosumeninfektion (Trypanosoma Brucei). Sie zeigen, daB der trypanozide Titer eines spezifischen Trypanosomenimmunserums nicht für die Umbildung des Normalstammes zum Rezidivstamm den maBgebenden Faktor darstellt, und machen es wahrscheinlich, daB neben den trypanoziden Antikörpern selbständige Serumsubstrate - von uns als Rezidivkörper bezeichnet - existieren, auf deren Reiz hin die Trypanosomen zur Ausbildung eines neuen rom Ausgangsstamm rerschiedenen dominanten Rezeptorenapparates gedrängt werden. Für die selbständige Existenz der Rezidivkörper im Immunserum neben den trypanoziden Immunkörpern spricht:

1. Die Dissonanz zwischen Trypanozidie und Rezidirstammbildungsvermögen der Trypanosomenimmunsera, wie sie im Reagenzglastersuch hervortritt.

2. Die stärkere Thermolabilität der rezidirstammbildenden Serumkomponenten, die bei 15 Minuten dauernder Erwärmung des Immunserums auf $60^{\circ}$ zerstört werden, während die trypanoziden Antikörper anscheinend intakt bleiben.

3. Daß die rezidirstammbildenden Eigenschaften spezifischer Trypanosomenimmunsera vorzugsweise an die Albuminfraktion gebunden erscheinen, während die trypanoziden Körper sich sowohl in der Albuminwie Globulinfraktion finden.

II. Entsprechend dem Gehalt der Immunsera an trypanoziden Substanzen und Rezidivbörpern ergeben sich bei Behandlung von Normaltrypanosomen im Reagenzglase mit genügenden, aber nicht letalen Immunserummengen folgende durch das Experiment bewiesene Möglichkeiten: 
1. Die Trypanosomen gehen ohne Verzögerung als Rezidivparasiten an.

2. Bei mäßiger bzw. starker Verzögerung der Infektion zeigen die angehenden Trypanosomen Rezidivstammeigenschaften.

3. Die Trypanosomen gelangen unter deutlicher bzw. beträchtlicher Verzögerung wieder als Normalparasiten zur Entwicklung.

4. Die angehenden Trypanosomen weisen Normalstamm- und Rezidivstammeigenschaften gleichzeitig auf.

III. Die erworbenen Rezidirstammeigenschaften brauchen nicht dauernd vererbt zu werden. Der Rückschlag des Rezidivstammes zum Ausgangsstamm muB jedoch nicht auf einem Rückschlag aller Parasiten beruhen, sondern kann sich auch bei Anwesenheit echter Mutationsformen durch Überwuchern von Trypanosomen vom Variationstypus, die zum Normalstamm zurückschlagen, rollziehen.

IV. Zwischen den im Reagenzglasversuch durch Immunserumkontakt erzeugten Rezidivstämmen und den im Verlaufe der Infektion spontan auftretenden Rezidirstämmen können biologische Unterschiede bei der Immunitätsreaktion bestehen.

V. Auch auf gleiche Art mit verschiedentägigem Immunserum im Reagenzglasversuch erzeugte Rezidirstämme können bei Anwendung der Immunitätsreaktion biologische Unterschiede zeigen.

VI. Mäuseimmunserum zeigt in vitro keine oder nur geringe trypanolytische Fähigkeiten, dagegen besitzt das Blut abgeheilter Trypanosomenmäuse in rivo starke trypanolytische Wirkungen. In Übereinstimmung hiermit steht das Fehlen von hämolytischem Komplement im Mäuseserum (Ritz), während Komplement in vivo bei Mäusen nachweisbar ist. 


\section{Literatur-Verzeichnis.}

Brann u. Teichmann, Versuche zur Immunisierung gegen Trypanosomen. Gustav Fischer, Jena 1912.

Braun, Beiträge zur Kenntnis des Komplementes. Biochem. Zeitschrift. 1911. S. 65 .

Ehrlich, Über Partialfanktionen der Zelle. Münchener med. Wochenschrift. 1909. Nr. 5.

Derselbe, Über Partialfunktionen der Zelle. (Nobel-Vortrag.) Beiträge zur experimentellen Pathologie u. Chemotherapie. Leipzig 1909. Akad. Verlagsgesellschaft.

Derselbe, Aus Theorie und Praxis der Chemotherapie. Folia Serologica. 1911. Bd. VII. Hft. 7. S. 697 .

Derselbe, Chemotherapeutische Trypanosomenstadien. Berliner klin. Wochenschrift. 1907. S. 311.

Ehrlich, Röhl und Gulbransen, Über serumfeste Trypanosomenstämme. Zeitschrift f. Immunitätsforschung. 1909. S. 296.

Ehrlich u. Shiga, Farbentherapeutische Versuche bei Trypanosomenerkrankung. Berliner klin. Wochenschrift. 1904. Nr. 13 u. 14.

Franke, Therapeutische Versuche bei Trypanosomenerkrankung. InauguralDissertation. GieBen 1905.

Laveran a. Mesnil, Trypanosomes et Trypanosomiases. Paris 1904.

Levaditi et Stanesco, Immunisation des spirilles par action des anticorps ,in vitro“. Bulletin de la Société de Pathologie Exotique. 1910. p. 353.

Levaditi u. Mutermilch, Recherches sur la méthode de Bordet et Gengou appliquée à l'étude des trypanosomiases. Zeitschrift f. Immunitätsforschung. 1909. Bd. II. S. 702.

Levaditi et Mc Intosh, Mécanisme de la création de races de trypanosomes, résistantes aux anticorps. Bulletin de la Société de Pathologie Exotique. 1910. p. 368.

Liefmann, Über den Mechanismus der Seroreaktion der Laes. Münchener med. Wochenschrift. 1909. Nr. 41.

Mesnil et Brimont, Sur les propriétés protectrices du sérum trypanosomiés. Races résistantes à ces serums. Annales de l'Institut Pasteur. 1909. p. 129.

Morgenroth u. Rosenthal, Ambozeptoren und Rezeptoren. I. Biochem. Zeitschrift. 1911. Bd. XXXVI. S. 190.

Diesel b en, Experimentell-therapentische Studien bei Trypanosomeninfektionen. I. Diese Zeitschrift. 1912. Bd. LXXI.

Dieselben, Sitzung d. Ges. der Charité-Arzte. Berliner klin. Wochenschrift. 1911. Nr. 2.

Neumann, Zur Kenntnis der Immunität bei experimenteller Trypanosomeninfektion. Diese Zeitschrift. 1911. Bd. LXIX.

Ritz, Über Antikörperbildung nnd Anaphylaxie bei weißen Mäusen. Zeitschrift f. Immunitätsforschung. 1911. Bd. IX. S. 333 . 